\title{
Manufacturing Methodology on Casting-Based Aluminium Matrix Composites: Systematic Review
}

\author{
José Grilo $^{1}{ }^{(D)}$, Vítor Hugo Carneiro ${ }^{1}$, José Carlos Teixeira ${ }^{2}$ and Hélder Puga ${ }^{1, * \mathbb{C}}$ \\ 1 CMEMS-Uminho, Department of Mechanical Engineering, University of Minho, \\ 4800-058 Guimarães, Portugal; id8983@alunos.uminho.pt (J.G.); d6705@dem.uminho.pt (V.H.C.) \\ 2 MEtRICs-UMinho, Department of Mechanical Engineering, University of Minho, \\ 4800-058 Guimarães, Portugal; jt@dem.uminho.pt \\ * Correspondence: puga@dem.uminho.pt; Tel.: +351-510-220
}

Citation: Grilo, J.; Carneiro, V.H.; Teixeira, J.C.; Puga, H. Manufacturing Methodology on Casting-Based Aluminium Matrix Composites: Systematic Review. Metals 2021, 11, 436. https://doi.org/10.3390/ met11030436

Academic Editor:

Alexander Vorozhtsov

Received: 3 February 2021

Accepted: 2 March 2021

Published: 6 March 2021

Publisher's Note: MDPI stays neutral with regard to jurisdictional claims in published maps and institutional affiliations.

Copyright: (c) 2021 by the authors. Licensee MDPI, Basel, Switzerland. This article is an open access article distributed under the terms and conditions of the Creative Commons Attribution (CC BY) license (https:// creativecommons.org/licenses/by/ $4.0 /)$.

\begin{abstract}
Ongoing industrial demand for lightweight materials has spiked the research interest in aluminium-based metal matrix composites for its specific properties. The amount of scientific publication available on the matter has led to the vast production of knowledge, which highlights the need for a systematic assessment if further progress is expected. In this paper, a systematic review of the published literature is conducted, according to the guidelines of the Preferred Reporting Items for Systematic Reviews and Meta-Analyses, on the Scopus and Web of Science databases were used in the literature search, which was completed on the 29 August 2020. The data of the research work is structured in the particle pre-processing stage and the melt processing stage. The present review clarifies the combined pair-wise effect of particles and the melt treatment performed on their wettability or dispersive or de-agglomerative capability, which allows to achieve their final mechanical properties.
\end{abstract}

Keywords: metal matrix composites; stir casting; aluminium; wetting; de-agglomeration; particle pre-processing; melt treatment; review report

\section{Introduction}

Current competitiveness in manufacturing industries implies that the overall technological processes and material processing must be optimized, meaning that there is an increasing interest in manufacturing routines based on the least material approaches. Indeed, the most effective route to achieve this goal is the enhancement of the overall mechanical properties, i.e., increasing the load-bearing capacity of materials to reduce their volume in structural applications. This route is aligned with current environmental concerns. For instance, the transportation industry is also searching for innovative materials to reduce the weight of their vehicles and thus decrease fuel consumption and $\mathrm{CO}_{2}$ emission [1-5].

Light alloys are current prominent solutions when compared to classic steel construction, occupying a significant quota in the manufacturing economy [6-8]. Their use generates a significant decrease in density (33\% and 77\%, respectively for $\mathrm{Al}$ and $\mathrm{Mg}$ alloys) when compared to steel $[9,10]$. Additionally, they may present interesting complementary mechanical properties, e.g., Mg alloys are regarded as high vibration damping alloys [11-14]. $\mathrm{Al}$ alloys, even though their density is relatively higher than $\mathrm{Mg}$ alloys, their processing may be regarded as simple. Combining both low melting temperatures relatively to steel and additional processing conditions that must be assured in the processing of $\mathrm{Mg}$ alloys to prevent severe exothermal reactions (e.g., protective atmosphere with toxic SF6 $[15,16]$ and specific coatings [17] to prevent rapid oxidation in casting processes [18]). In fact, the physical and mechanical properties of aluminium alloys are rather tailorable [19-21], considering that the correct processing (e.g., precipitation/work hardening and forming/machining) [22,23] and alloying (e.g., soluble elements and master alloys) [24,25] is 
performed, including variable load-bearing capacity, hysteretic damping, tribological and corrosion properties.

Current developments on the processing of aluminium alloys are frequently related to melt (e.g., alloying, degassing, refinement and modification) [26-29], solid (e.g., precipitation/work hardening, forming/machining) [30-34] and hybrid (powder metallurgy and additive manufacturing) $[35,36]$ processes. However, some authors suggest that conventional alloys themselves have reached their limit in terms of mechanical properties has been spreading inside the scientific community [37]. Al-Si alloys are classic alloys, being commonly used in hypo-, hyper- and eutectic configurations [38]. They are also frequently alloyed in ternary / quaternary compositions to make them heat treatable (i.e., including soluble elements such as $\mathrm{Si}, \mathrm{Mg}$ and $\mathrm{Cu}$ ) [39]. These alloys are considered very versatile, being able to be molten in a wide range of crucible materials, and cast into different moulding materials to obtain complex geometries with a high quality-index [40,41].

Metal matrix composites (MMCs) have been considered a promising solution to the limiting mechanical properties of light alloys [42]. Numerous studies have shown that the addition of fine reinforcement phases into a metallic matrix generates significant benefits, e.g., the increase in yield strength due to an Orowan mechanism [43-45] and efficiently enhance internal friction (i.e., damping) [46,47]. Even though the advent of MMC fabrication occurred in the 1950s, their implementation in large industrial scales is still a challenge [48].

Current processing of MMCs may be divided into three approaches according to the matrix state during particle introduction: (i) solid; (ii) semi-solid; and (iii) liquid [49]. Solid and semi-solid routes usually use powder metallurgy and sintering techniques, in which reinforcement bonding is promoted by a well-defined temperature-pressure interaction, however, due to limitations in component volume/shape, the application of these techniques on an industrial scale is not really feasible. Liquid-based MMC fabrication approaches (e.g., casting) remain an attractive option with a wide room for improvement and innovation. Al-based MMCs are especially successful in enhancing overall load-bearing [50], damping [51], tribological [52], electrical [53] and heat conduction [54] properties.

Still, the liquid MMC processing approach presents some issues, e.g., the increase in reinforcement content usually translates to an increase in porosity, by either gas transport in the interface layer or pore nucleation due to matrix-reinforcement thermal expansion gradients $[55,56]$. Another issue is the lack of heterogeneous reinforcement distribution and particle agglomeration (i.e., particle clusters) [57-59]. In this context, particle distribution and porosity problems can often be related to insufficient melt-reinforcement wetting, i.e., an efficient interfacial bonding by melt surface tension and contact angle [60]. Even though numerous researchers have recommended pre-processing techniques (e.g., ball milling, heat treatment, particle oxidization, coating, composite powders) to solve this issue, there seems to be no specific guidelines for these processes and their combination.

A common technique to disperse reinforcement particles in liquid MMC processes is stir casting [61]. Stirring itself, not only has a dispersive function in the process, but it was also found to have positive wetting effects, however, these effects are dependent on stirring times and speeds, blade size and angles at different melt temperatures cycles, and additive/wetting agents volume fraction. Recently, the authors have shown [62] that ultrasonic cavitation-induced streaming in Al-Si melts may be an efficient route to generate microparticle distribution and wettability.

Given the different methodologies in liquid MMC manufacturing (e.g., pre-processing, temperatures, times, etc.), the present work synthesises the most common pathways based on Al-Si matrix, regarding their overall efficiency. Methods and experimental procedures are and discussed in the optics of the casting process for the manufacturing of low-cost MMCs. The present review clarifies the combined pair-wise effect of particles and the melt treatment performed on their final mechanical properties. Pre-processing techniques are evaluated regarding matrix-reinforcement wettability and microstructural 
side-effects, while melt processing techniques are reviewed on their dispersive and deagglomerative capacity.

\section{Methods}

The methodology employed in the search and review of the literature follows the guidelines of Preferred Reporting Items for Systematic Reviews and Meta-Analyses (PRISMA), which was originally developed to help authors to report a wide array of systematic reviews [63].

\subsection{Search Strategy}

A systematic search of the literature was carried out until 29 August 2020, with the use of the keywords 'Aluminium', 'Matrix', 'Composite', 'Reinforced', 'Molten', 'Melt' and 'Cast' along with the Boolean operators AND, OR and NOT. Scopus and Web of Science database were used to accurately achieve the desired results.

Database specific wildcards were also introduced to capture the differences in designations as well as standard definitions, which includes American/British spelling of $\mathrm{Al}$; ISO alloy designation of Al-based alloys but not aluminium alloys ( $\mathrm{Al}-\mathrm{Si}=/=\mathrm{Mg}-\mathrm{Al}$ ); $\mathrm{Al}-$ based composite instead of Al-reinforced composite among others.

\subsection{Bibliographic Selection}

The selected articles were compiled and merged in an Excel sheet, to proceed to data cleansing. This preliminary stage includes the removal of duplicates, the removal of articles from predatory Publishers and Journals, the removal of articles without a DOI reference, the removal of miscategorised articles (Review, Abstract only and Proceedings), the removal of articles based on solid or additive manufacturing processes and the removal of articles centred on non-aluminium alloys or non-metallic matrix composites. After a systematic review of the carefully chosen literature, the results of the authors were compared and the differentiating aspects in their conclusions/final decisions were discussed until a consensus was reached.

\section{Results}

The flowchart of Figure 1 represents the systematic research technique used in this work, according to PRISMA. After the data cleansing and exclusion through the abstract reading, 216 full papers were analysed, of which 20 are selected for this work.

To the date of the review, casting-based MMC represents on average $31 \%$ of all MMC publications available at the selected bibliography databases. Current aluminium metal matrix composite publication can be classified as confirmatory or exploratory with regard to the pre-processing of the reinforcement particle or the in melt processing and incorporation of the particles. Figure 2 illustrates the evolution of MMC publications of the six most commonly found reinforcement particles in the literature. Based on these findings, $\mathrm{Al}_{2} \mathrm{O}_{3}, \mathrm{SiC}$ and $\mathrm{B}_{4} \mathrm{C}$ are selected in order to further detail their differing aspects in casting composite processing. Likewise, Table 1 summarises the research findings on reinforcement content, optimal pre-processing parameters and limitations which most influence the wettability as well as its resulting impact on material properties. Table 2 reports the various melt manufacturing methodologies adopted in the bibliography as well as its resulting impact on particle dispersion and material properties. 


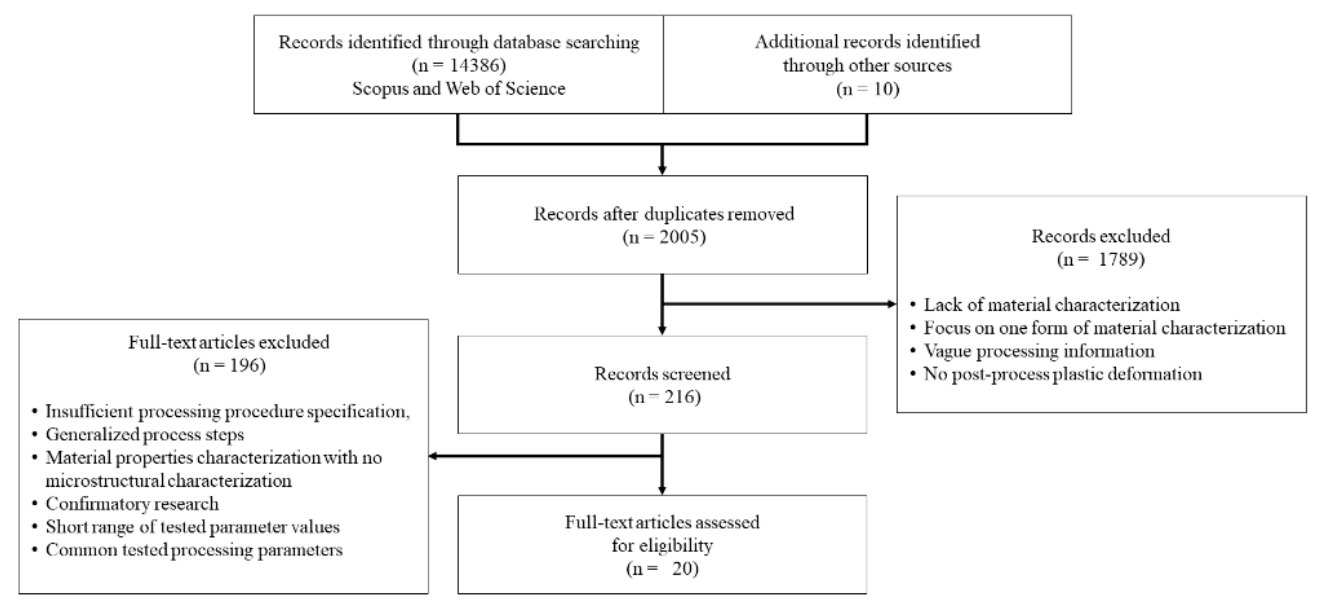

Figure 1. Flowchart of the systematic review.

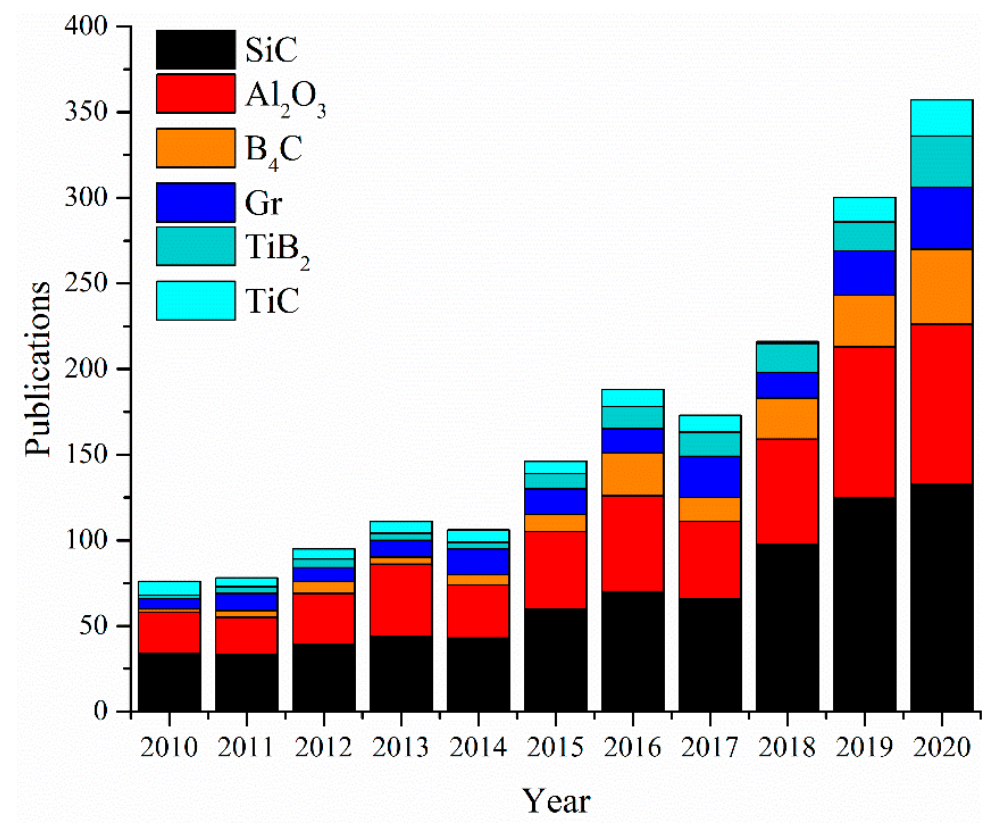

Figure 2. Number of publications related to Al-based metal matrix composites (MMC) and specific to casting.

Table 1. Reinforcement particle pre-processing stage.

\begin{tabular}{|c|c|c|}
\hline Ref. & Particle & Results and Observation \\
\hline [64] & $\begin{array}{l}\mathrm{Al}_{2} \mathrm{O}_{3} \sim 30 \mu \mathrm{m} ; \text { Qnt: }\{2,4,6,8\} \text { wt. } \% \\
\text { PreH: } 800^{\circ} \mathrm{C}\end{array}$ & $\begin{array}{l}\text { - Hardness and UTS increase linearly with the reinforcement content } \\
\text { - Homogenous distribution with an apparent good bonding }\end{array}$ \\
\hline [65] & $\begin{array}{l}\mathrm{Al}_{2} \mathrm{O}_{3}\{10 \mu \mathrm{m}, 100 \mathrm{~nm}\}+\mathrm{Al} 74 \mu \mathrm{m}+\mathrm{Mg} \\
60 \mu \mathrm{m} \\
\text { B.mill (ball, b2p): }([7,25] \mathrm{mm}, 10: 1) \\
\text { B.mill (N, } \Delta \mathrm{t}):(480 \mathrm{rpm},\{3,6,9\}+3 \mathrm{~h}) \\
\text { B.mill.Gas: Argon } \\
\text { Press (p): } 1 \mathrm{MPa}\end{array}$ & $\begin{array}{l}\text { - Ball milling reduced powders aspect ratio and surface roughness } \\
\text { Ball milling induced a close contact between particles along with a } \\
\text { uniform distribution } \\
\text { - Cold pressing improved wettability, which induced a uniform } \\
\text { distribution and better tensile properties. } \\
\text { - Cold pressing powders are reported to decrease stirring turbulence }\end{array}$ \\
\hline
\end{tabular}


Table 1. Cont.

\begin{tabular}{|c|c|c|}
\hline Ref. & Particle & Results and Observation \\
\hline$[66]$ & $\begin{array}{l}\mathrm{Al}_{2} \mathrm{O}_{3}\{30 \mathrm{~nm}, 1 \mu \mathrm{m}, 60 \mu \mathrm{m}\} \\
\text { B.mill.(ball, b2p): }(20 \mathrm{~mm}, 10: 1) \\
\text { B.mill (N, } \Delta \mathrm{t}):(500 \mathrm{rpm}, 30 \mathrm{~h}+\{30 \mathrm{~min} \text {, } \\
15 \mathrm{~h}\}) \\
\text { B.mill.Gas: Argon; } \\
\text { US. } \Delta \mathrm{t}: 90 \mathrm{~min} \\
\text { Press (p, } \mathrm{T}, \Delta \mathrm{t}):\left(128 \mathrm{Mpa}, 400^{\circ} \mathrm{C}, 30 \mathrm{~min}\right)\end{array}$ & $\begin{array}{l}\text { - } \quad \text { all milling } \mathrm{Al}_{2} \mathrm{O}_{3 n p} \text { resulted in a powder superior surface along with } \\
\text { - } \quad \text { uniform distribution } \\
\text { - } \quad \text { Higher particles sizes decrease relative density and hardness }\end{array}$ \\
\hline
\end{tabular}

[67] SiC $15 \mu \mathrm{m}$; Qnt: $\{0.5,1,1.5\} \mathrm{wt} . \%$ PreH: $\{600,700,800\}^{\circ} \mathrm{C}$
- $\quad$ wt.\% SiC and pre-heating have strong effect on UTS and hardness

- Composite porosity is directly proportional to wt.\% SiC stirring speed, but a minimal is reported at $700{ }^{\circ} \mathrm{C}$ of pre-heating temperature
[68]

$\mathrm{Al}_{2} \mathrm{O}_{3}\{65 \mu \mathrm{m}, 79 \mathrm{~nm}\} ;$ Qnt: $\{0.5,1,1.5\}$

wt. \%

PreH: $\left\{700,750{ }^{\circ} \mathrm{C}\{20 \mathrm{~min}, 2 \mathrm{~h}\}\right.$

\section{SiC; Qnt: 10 g}

[69] Clean: $\left\{\mathrm{NaCl}, \mathrm{SnCl}_{2}, \mathrm{NH}_{4} \mathrm{Cl}, \mathrm{PdCl}_{2}\right\}$

Clean $(\mathrm{c}, \Delta \mathrm{t}):([10,50] \mathrm{g} / \mathrm{L},[0,120] \mathrm{min})$
- $\quad$ Best mechanical properties obtain for $0.5 \mathrm{wt} . \% \mathrm{Al}_{2} \mathrm{O}_{3 \mathrm{np}}$, for which, higher wt.\% properties would decrease

- $\quad$ Despite the increasing porosity, $\mathrm{Al}_{2} \mathrm{O}_{3 \mathrm{mp}}$ sees an increase in mechanical properties for higher wt. $\%$

- All method effectively inhibits $\mathrm{Al}_{4} \mathrm{C}_{3}$ formation $\left(\mathrm{SnCl}_{2}>\mathrm{PdCl}_{2}>\right.$ $\mathrm{NaCl}>\mathrm{NH}_{4} \mathrm{Cl}$ )

- $\quad$ Best mechanical properties reported by $\mathrm{NaCl}(40 \mathrm{~g} / \mathrm{L}$ at $100 \mathrm{~min})$ followed by $\mathrm{PdCl}_{2}(1 \mathrm{~g} / \mathrm{L}$ at $120 \mathrm{~min}), \mathrm{SnCl}_{2}(40 \mathrm{~g} / \mathrm{L}$ at $60 \mathrm{~min})$, and $\mathrm{NH}_{4} \mathrm{Cl}(15 \mathrm{~g} / \mathrm{L}$ at $60 \mathrm{~min})$
[70] $\quad \mathrm{B}_{4} \mathrm{C} 20 \mu \mathrm{m}$; Qnt: $10 \%$ PreH: $[250,600]{ }^{\circ} \mathrm{C}$
- $\quad$ Best UTS and hardness for particle preheat at $250{ }^{\circ} \mathrm{C}$

- Particle heat treatment above $300{ }^{\circ} \mathrm{C}$, creates $\mathrm{B}_{2} \mathrm{O}_{3}$ phase causing sintering and inducing agglomeration in the melt
- Small clusters at 20 vol. $\%$ of $\mathrm{B}_{4} \mathrm{C}$

- Particles were reduced to $30 \mu \mathrm{m}$ by stirring

- No other phases were formed in the $\mathrm{B}_{4} \mathrm{C}$ interface
[71] $\mathrm{B}_{4} \mathrm{C} 100 \mu \mathrm{m}$; Qnt: $\{0,5,10,15,20\}$ vol.\% PreH: $300{ }^{\circ} \mathrm{C}$
- $\quad$ Coating significantly improved particle wettability and mitigated segregation and agglomeration defects

- $\quad$ Best mechanical properties are reported for $\mathrm{Ni}$ coating followed by $\mathrm{Co}$
$\mathrm{Al}_{2} \mathrm{O}_{3} 50$ nm; Qnt: [1, 10] wt.\% Coat: $\{\mathrm{Cu}, \mathrm{Ni}, \mathrm{Co}\}$
- $\quad$ The formation of $\mathrm{a} \mathrm{Ti}_{5} \mathrm{Si}_{3}$ layer improves $\mathrm{SiC} / \mathrm{Ti}$ interface wettability

- Mechanical property enhancement of the coating is justified through the uniform dispersion, smooth coating interface and a porosity reduction in the composite
SiC $5 \mu \mathrm{m}$; Qnt: 3 vol.\%

Coat: $\{\mathrm{Cu}, \mathrm{Ni}\}$

Pre.H: $[700,1100]{ }^{\circ} \mathrm{C}(3 \mathrm{~h})$
- Mechanical properties of the $\mathrm{SiC}$ composites can be ranked as: $\mathrm{SiO}_{2}$ oxide layer, $\mathrm{Ni}$ coating, $\mathrm{Cu}$ coating

- $\quad$ Tensile properties increase for higher heat treatment temperatures but decrease for longer periods

Qnt—quantity; B.mill—ball milling; ball—milling ball diameter; N—rotational speed; Gas—protective gas; b2p—ball to powder ratio; US— ultrasonic dispersion; Clean—cleaning method/agent; c—concentration; Coat—coating; PreH—pre-heating; Press—Pressing; $\mathrm{p}$ - pressure; T-temperature; $\Delta \mathrm{t}$-time; UTS—ultimate tensile strength. 
Table 2. Particle melt processing stage.

\begin{tabular}{|c|c|c|c|}
\hline Ref. & $\begin{array}{l}\text { Materials and } \\
\text { Pre-Processing }\end{array}$ & Melt Processing & Results and Observation \\
\hline [75] & $\begin{array}{l}\mathrm{A} 356 /\left(\mathrm{B}_{4} \mathrm{C} 1 \mu \mathrm{m}+\mathrm{Al} 16 \mu \mathrm{m}\right) \\
\text { Qnt: }\{0 ; 5 ; 10 ; 15\} \text { vol. } \%\end{array}$ & $\begin{array}{l}\mathrm{T}:\{750,850,950\}{ }^{\circ} \mathrm{C} \\
\text { Carrier: Al foil; Intro: Vortex } \\
\text { Stir }(\mathrm{N}, \Delta \mathrm{t}):(300 \mathrm{rpm}, 13 \mathrm{~min})\end{array}$ & $\begin{array}{l}\text { - } \quad \text { Best UTS, elongation and toughness at } 850{ }^{\circ} \mathrm{C} \\
\text { melt temperature with } 10 \text { vol. } \% \mathrm{~B}_{4} \mathrm{C} \\
\text { Best } \mathrm{H} \text { at } 950{ }^{\circ} \mathrm{C} \text { melt temperature with } \\
15 \text { vol. } \% \mathrm{~B}_{4} \mathrm{C} \\
\text { - } \quad \begin{array}{l}\text { Increasing porosity proportional to particle } \\
\text { content and melt temperature }\end{array} \\
\text { - } \begin{array}{l}\text { Higher agglomeration and poorer wetting at } \\
\text { lower temperature verified my } \\
\text { mechanical properties }\end{array}\end{array}$ \\
\hline
\end{tabular}

- Optimal mechanical properties were verified for a

T: $\{750,850,950\}^{\circ} \mathrm{C}$

A356/( $\left.\mathrm{B}_{4} \mathrm{C} \sim 0.2 \mu \mathrm{m}\right)$

[76] Qnt: 3 wt. $\%$

PreH: $200{ }^{\circ} \mathrm{C}$
Intro: Vortex

Stir (B\#, B $\theta):\left(4,45^{\circ}\right)$

Stir (N, $\Delta \mathrm{t}):(300 \mathrm{rpm},\{10,15$, 20\} $\min$ ) stirring period of $15 \mathrm{~min}$, after which, properties report a downwards tendency

- Higher melt temperature than $850{ }^{\circ} \mathrm{C}$ lead to the formation of undesirable chemical compounds and gas porosities

- Lower temperatures report a lower wettability and induce a non-uniform distribution

$\mathrm{A} 356 /(\mathrm{SiC} 40 \mathrm{~nm}+\mathrm{Al} 65 \mu \mathrm{m})]$ Qnt.SiC/Al: $\{0,1,2\}$ wt.\% PreH: $850{ }^{\circ} \mathrm{C}(2 \mathrm{~h})$

\section{T1: $720{ }^{\circ} \mathrm{C}$}

Degass: Argon (10 min)

Intro: Vortex

Stir (B\#, N, $\Delta \mathrm{t}, \mathrm{T}):(4,180 \mathrm{rpm}$, $\left.15 \mathrm{~min}, 680^{\circ} \mathrm{C}\right)$ $\mathrm{US}(\mathrm{P}, \mathrm{f}, \Delta \mathrm{t}):(2.8 \mathrm{~kW}, 20 \mathrm{kHz}$, $[0.5,5] \mathrm{min})$
- UST refining effect on grain size and SDAS is observable up until 2 min treatment period, after which (until $5 \mathrm{~min}$ ), the gains are negligible

- Maximum UTS, YS, elongation is achieved for $2 \mathrm{wt} . \%(\mathrm{SiC} / \mathrm{Al})_{\mathrm{p}}$ at longer UST treatment periods and higher applied pressure

- $\quad$ Optimum parameters are set at $2 \mathrm{~min}$ treatment and $100 \mathrm{MPa}$ pressure
T: $\{800,1000\}^{\circ} \mathrm{C}$

Add: 10 gr Cryolite

[78]

A356/ ${ }_{4} \mathrm{C}<30 \mu \mathrm{m}$

Qnt: $\{5,10,15\}$ vol.\%
Carrier: Al Foil; Intro: Vortex

Stir (B\#, B $\theta):\left(4,45^{\circ}\right)$

Stir $(\mathrm{N}, \Delta \mathrm{t}):([350,400]$, $\Delta \mathrm{t}: 0.8$ Qnt)
- $\quad$ Recommended 4 min stirring for each 5 vol.\% $\mathrm{B}_{4} \mathrm{C}$ introduced

- Mechanical properties increase with reinforce content until low wetting affects its gains, even with an increase in wettability for higher melt temperatures

- Brittleness was attributed to the increase rate of oxygen absorption

- It is suggested that a stirring period too short will result in a non- uniform dispersion while a higher stirring period might risks agglomeration and projection of the particles to the crucible walls

- Decrease in particle size improves distribution however it can also contribute to more agglomeration

$\mathrm{T}$ (i): $(800,600,730){ }^{\circ} \mathrm{C}$

Degass: $\mathrm{N}_{2}$

Intro: Vortex

$\mathrm{A} 356 / \mathrm{SiC}_{\mathrm{p}}$ Size: $\{4.5,9.3$,

[79] 12.8$\} \mu \mathrm{m}$

Qnt: 10 vol.\%

PreH: $400{ }^{\circ} \mathrm{C}(2 \mathrm{~h})$
Stir (B\#, B $\theta)$ : $\left(2,45^{\circ}\right)$

Stir (A).(N, $\Delta \mathrm{t}, \mathrm{T}):(650 \mathrm{rpm}$,

$\left.5 \min ,\{600,730\}^{\circ} \mathrm{C}\right)$

Rotor (B).(N, $\Delta t, T):(\{650$, $5000\} \mathrm{rpm}, 5 \mathrm{~min},\{600$, $730{ }^{\circ} \mathrm{C}$ )
- Metal shearing suggest to de-agglomerate cluster pre-introduction.

- $\quad$ This contributed to an improvement in melt fluidity as a reduction of viscosity

- $\quad$ Such contribution improved general mechanical and tribological properties

- Although shear reduced the variance of the particle size, its material properties often show a more scattered data when compared with the regular impeller stirring 
Table 2. Cont.

\begin{tabular}{|c|c|c|c|}
\hline Ref. & $\begin{array}{l}\text { Materials and } \\
\text { Pre-Processing }\end{array}$ & Melt Processing & Results and Observation \\
\hline [80] & $\begin{array}{l}\text { Al-Si } /(\mathrm{SiC} 20 \mu \mathrm{m}) \\
\text { Qnt: }\{6,810\} \text { vol. } \% \\
\text { Pre.H: } 600^{\circ} \mathrm{C}\end{array}$ & $\begin{array}{l}\text { T: }\left[580,620{ }^{\circ} \mathrm{C}\right. \\
\text { Carrier: Al foil } \\
\operatorname{EM}(\mathrm{B} \theta, \mathrm{B} \varphi):\left(\left\{0^{\circ}, 30^{\circ}, 60^{\circ},\right.\right. \\
\left.\left.90^{\circ}\right\},\left\{0^{\circ}, 20^{\circ}, 40^{\circ}\right\}\right) \\
\operatorname{EM}(\mathrm{N}):\{1400,1700,2000\} \mathrm{rpm}\end{array}$ & $\begin{array}{l}\text { - Removing air during the stirring stage decreased } \\
\text { air entrapment and resulting porosity } \\
\text { - Gravitational segregation and centrifugal } \\
\text { clustering was avoided with a blade angle of } 30^{\circ} \\
\text { (B } \theta \text {, horizontal) and } 20^{\circ}(\mathrm{B} \varphi \text {, radial) } \\
\text { uniform distribution was achieved with a } 3 \mathrm{~min} \\
\text { stirring at } 1400-2000 \mathrm{rpm}\end{array}$ \\
\hline
\end{tabular}

$\mathrm{A} 356 /\left\{\mathrm{Al}_{2} \mathrm{O}_{3} 20 \mathrm{~nm}\right.$, $\mathrm{SiC} 40 \mathrm{~nm}$,

[81] $\left.\left(\mathrm{Al}_{2} \mathrm{O}_{3} 20 \mathrm{~nm}+\mathrm{SiC} 40 \mathrm{~nm}\right)\right\}$

Qnt: $\{2,2,1: 1\}$ wt.\%

Pre.H: $150{ }^{\circ} \mathrm{C}(2 \mathrm{~h})$
T: $700{ }^{\circ} \mathrm{C}$

Degass: $\mathrm{C}_{2} \mathrm{Cl}_{6}$

P.Gas: Argon

Intro: Injection

US: UNS
- $\quad$ Best UTS, YS and elongation by $\left(\mathrm{Al}_{2} \mathrm{O}_{3} / \mathrm{SiC} / \mathrm{Al}\right)_{\mathrm{p}}$

- Lower enhancement on mechanical properties on $\left(\mathrm{Al}_{2} \mathrm{O}_{3} / \mathrm{Al}\right)_{\mathrm{p}}$ and $(\mathrm{SiC} / \mathrm{Al})_{\mathrm{p}}$ was attributed to the agglomeration tendency

- Authors infer that composite powder performance was caused by a greater interfacial energy barrier than the Brownian potential
[82] $\mathrm{Mg} 40 \mu \mathrm{m})$

Qnt: SiC 5 vol.\%, Mg 1 wt.\%
$\mathrm{T}$ (i): $(700,\{650,607\}){ }^{\circ} \mathrm{C}$

Intro: Injection

Stir $(\mathrm{N}, \Delta \mathrm{t}):(500 \mathrm{rpm},\{12$,

22\} $\min$ )
- $\quad$ Particle injection significantly enhanced distribution and avoid clustering

- Composite particles resulted in smaller incorporated $\mathrm{SiC}, \mathrm{SDAS}$ and grain size

- $\quad$ The semi-solid process produced a finer non-dendrite structure and better mechanical properties, even though neither method had significant impact on $\mathrm{SiC}$ particle size
- UST breaking the dendritic structure enabled the formation of more globular grains

- $\quad \mathrm{SiC}$ and $\mathrm{Al}_{2} \mathrm{O}_{3}$ reinforced $\mathrm{MMC}$ report an increase in UST and elongation compared to an unreinforced degassed sample
[83] $20 \mathrm{~nm}\}$

Qnt: 1 wt.\%
P.Gas: Argon

Degass: UST

Intro: Injection

US (P,f): $(1.75 \mathrm{~kW}, 18 \mathrm{kHz})$

N/A—not applicable; UNS—Unspecified; (i)—multi-step method; (A)—alternative method; Qnt—quantity; PreH—pre-heating; T—melt temperature; P.Gas—protective gas; Carrier-carrier agent; Intro-introduction method; Add—additive; Degass—degassing method; Stir-impeller stirring; EM—electromagnetic stirring; Rotor—rotor stirring; B\#—number of blades; B —-blade angle (Horizontal plane); $\mathrm{B} \varphi$ —blade angle (radial plane); $\mathrm{N}$ —stirring speed; UST—ultrasonic melt treatment; $\Delta \mathrm{t}$-time; UTS—ultimate tensile strength; YS—yield strength; H—hardness; SDAS—secondary dendrite arm spacing.

\section{Discussion}

This chapter details the discussion regarding composite manufacturing and as such, is subdivided in pre-processing and melt processing.

The pre-processing subchapter addresses any technique or parameters before the introduction of the reinforcement particles in the melt to enhance the wettability between the particle and the melt. These include composite ball milling, wetting agents, method coating, oxidization and heat treatment. Considering that testing the contact angle is not viable in a casting scenario, the assessment of a successful wetting is carried out by qualitative visual inspection of the microstructure [84,85], particle image analysis [86-89], particle residuals or rejected collection [90,91].

The melt processing sub-chapter addresses any methodology, technique and inherent parameters which aims to distribute and de-agglomerate particles upon introduction in the melt. The presented techniques have an impact on particle wetting and sample microstructure which cannot be evaluated as isolated variables. The assessment of a uniform distribution is carried out by qualitative visual inspection of the microstructure $[69,84,85]$, 
material property enhancement $[77,92,93]$, particle image analysis regarding distribution along with agglomeration $[88,89,94]$ and hardness profile along a specific axis [95].

\subsection{Pre-Processing \\ 4.1.1. Coating}

Given the low wettability of ceramic particles $[96,97]$, metallic coatings or oxidation of the interface is often performed before the reinforcement is introduced in the melt to improve reinforcement-matrix bonding. Among the available options, nickel and copper are the most common choices for electroless deposition coating [72,98-101].

Pourhosseini et al. have studied the effects of $\mathrm{Cu}, \mathrm{Ni}$ and Co coatings on the wettability of $\mathrm{Al}_{2} \mathrm{O}_{3 n p}$ through electroless deposition in $\mathrm{Al} / \mathrm{Al}_{2} \mathrm{O}_{3}$ stir casting [72]. When compared to uncoated samples, $\mathrm{Ni}, \mathrm{Cu}$ and $\mathrm{Co}$ report enhancement with regards to tensile properties and hardness, respectively. Ni coating performance was justified given its distribution and lesser agglomeration as well as the formation of the $\mathrm{Al}_{3} \mathrm{Ni}$ phase in the $\mathrm{Al}_{2} \mathrm{O}_{3}$ interface. Mousavian et al. have studied the effects of $\mathrm{Cu}, \mathrm{Ni}$ and Co coating of $\mathrm{SiC}_{\mathrm{mp}}$ through electroless deposition in $\mathrm{Al} / \mathrm{SiC}$ Stir casting [102]. The resultant mechanical properties show that $\mathrm{Cu}, \mathrm{Co}$, Ni have effectively reinforced the Al-based composite. The authors hypothesised that higher incorporation percentage is promoted by the endothermic reactions with molten aluminium. Yang et al. have studied the effect of Ti coatings on the wettability and distribution of particles in $\mathrm{Al} 2014 / \mathrm{SiC}_{\mathrm{p}}$ stir-casting [73]. It was reported that the formation of a $\mathrm{Ti}_{5} \mathrm{Si}_{3}$ in the $\mathrm{SiC} / \mathrm{Ti}$ interface would decrease its contact angle in a shorter period for $800{ }^{\circ} \mathrm{C}$, leading to higher interfacial energy when compared with the uncoated samples.

\subsubsection{Oxidation}

While oxygen solubility is extremely low in liquid aluminium, the $\mathrm{Al}$ element presents a very high affinity for oxygen. It is suggested that $\mathrm{Al}$ can alter the interfacial chemistry by forming an oxide layer with a lower $\mathrm{O} /$ metal ratio than in the bulk oxide that may improve wetting [60]. Zhang et al. have studied the bonding effects of oxidised, $\mathrm{Ni}$ and $\mathrm{Cu}$ coated $\mathrm{SiC}_{\mathrm{p}}$ of an $\mathrm{Al} / \mathrm{SiC}$ through semi-solid stir casting [74]. Results report that the $\mathrm{SiC}_{\mathrm{p}}$ oxidization has the most significant impact on yield strength, ultimate tensile strength and fracture strain of all tested samples. The authors show that the developed $\mathrm{SiO}_{2}$ layer improves the interfacial wettability by reactions with $\mathrm{Al}$ and $\mathrm{Mg}$ elements in the melt, thus producing its oxidised phases $\mathrm{Al}_{2} \mathrm{O}_{3}, \mathrm{MgO}$ and $\mathrm{MgAl}_{2} \mathrm{O}_{4}$. The wettability effect of $\mathrm{SiO}_{2}$ is in agreement with other works [88]. Similarly, Mahesh et al. have investigated the effects of heat treating $\mathrm{B}_{4} \mathrm{C}_{\mathrm{p}}$ on the microstructure and mechanical properties of $\mathrm{Al} / \mathrm{B}_{4} \mathrm{C}$ by stir casting [70]. Even though a uniform distribution of the particles was achieved with heat treatment at $250{ }^{\circ} \mathrm{C}$. The authors state that above $300{ }^{\circ} \mathrm{C}$ particles form a glassy boric oxide phase $\left(\mathrm{B}_{2} \mathrm{O}_{3}\right)$, which causes sintering and will eventually induce agglomeration in the melt.

\subsubsection{Pre-Heating}

When a mismatch of thermal expansion coefficients exists between the reinforcement and the main matrix, frequent for most ceramic-reinforced MMC, higher temperatures can induce porosity and dislocations in the vicinity of the particle [75]. Additionally, the increase in reinforcement content, higher casting temperature increases the probability of gas solution in the melt, which will later result in solidification defects [103]. In fact, reinforcement particles tend to agglomerate in lower melt temperatures due to higher viscosity [75] (p. 4479).

Azadi et al. compared the effect of ball milling and heat treatment of $\mathrm{SiO}_{2 n p}$ on mechanical and tribological properties. The presence of $\mathrm{SiO}_{2 \mathrm{p}}$ enhanced hardness, elastic modulus, compression yield strength but decreased tensile strength, elongation and toughness. It was reported that the pre-heating of $1 \mathrm{wt} . \%$ reinforcement particles at $400{ }^{\circ} \mathrm{C}$ improved its wetting and material properties while promoting porosity defects [104]. Ghandvar et al. have produced A356-based composites reinforced with $20 \mathrm{wt} . \% \mathrm{SiC}_{\mathrm{p}}$ through a semisolid 
process. The authors compared the effects of different particle pretreatments regarding surface treatment, preheating and the use of a wetting agent [105]. It is reported that the pretreatment enhanced the particle/matrix wettability as well as its distribution, which was then further improved with the addition of $1 \mathrm{wt} . \% \mathrm{Mg}$. The increase in hardness, UTS and elongation was associated with the removal of impurities during cleaning and the formation of $\mathrm{SiO}_{2}$ during the heating.

\subsubsection{Cleaning}

Adeosun et al. have studied the effects of cleaning time and reagents in a $6011 / \mathrm{SiC}_{\mathrm{p}}$ composite particle wettability and mechanical properties, including the use of $\mathrm{NaCl}, \mathrm{SnCl}_{2}$, $\mathrm{NH}_{4} \mathrm{Cl}$ and $\mathrm{PdCl}_{2}$ [69]. Wetting reagents were proven effective as they improved interfacial bonding and inhibited the formation of $\mathrm{Al}_{4} \mathrm{C}_{3}$, although residual particle clustering could be observed. Optimal ductility and hardness are reported by $\mathrm{SnCl}_{2}$ and $\mathrm{PdCl}_{2}$ with clearing period of 100-120 min followed by a 60 min cleaning with $\mathrm{NaCl}$ or $\mathrm{NH}_{4} \mathrm{Cl}$. Similar conclusions were drawn out by other authors $[105,106]$.

\subsection{Melt Processing}

Shared by any MMC processing method, the reinforcement processing can potentially limit the efficiency for particle-matrix bonding. In the MMC casting route, high contact angle and poor chemical bonding between the reinforcement particle-matrix are often caused by poor wettability [107]. Contact angle can be understood as the angle formed by the interface between a non-reactive liquid and flat, smooth and chemically homogeneous solid surface in a state of equilibrium at a given temperature [60]. As depicted in Figure 3 , the impact of temperature on the wetting behaviour of the metal/ceramic pair is evidently positive. Even so, there is a sparse distribution of the data points that can be attributed to the interaction with the available atmospheric content, as thoroughly reported in [96,108-114], being dependent on sample purity, pre-treatment, crystallization, oxidization with available oxygen molecules, the experimental procedure itself, among others [115].

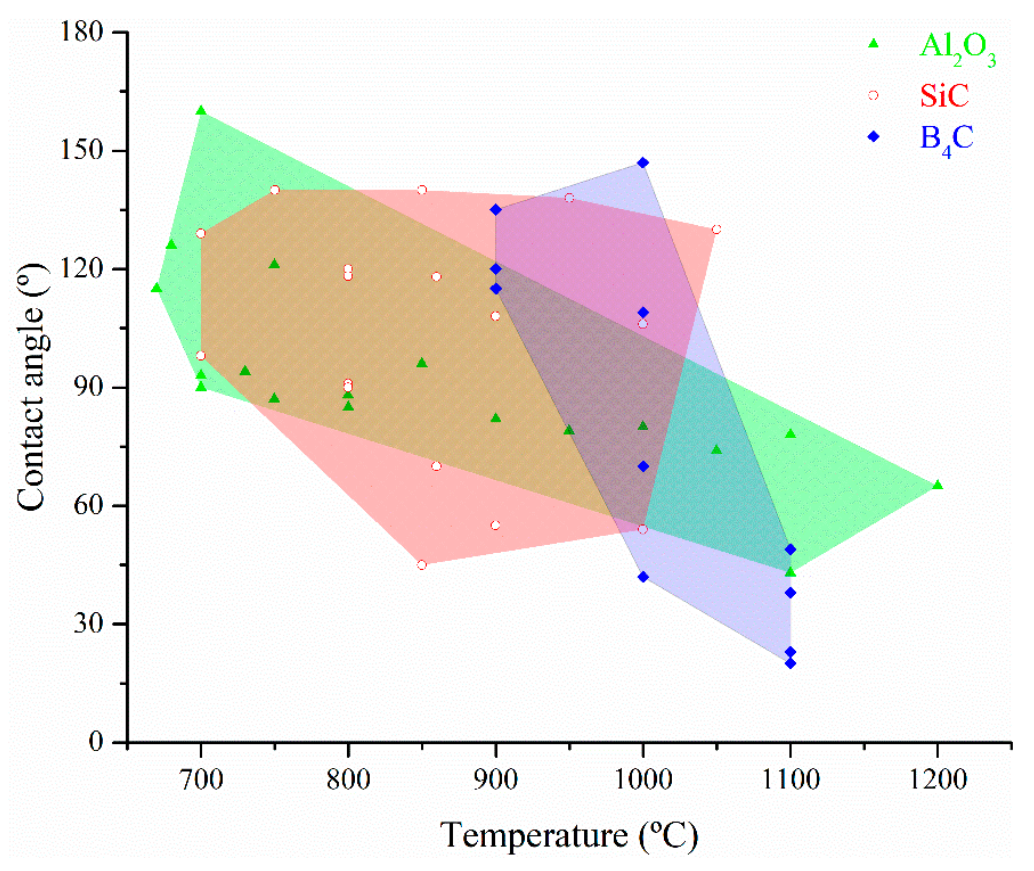

Figure 3. Contact angle of $\mathrm{Al}$ on $\mathrm{Al}_{2} \mathrm{O}_{3}, \mathrm{SiC}$ and $\mathrm{B}_{4} \mathrm{C}$ as a function of temperature [96,108-114].

\subsubsection{Melt Temperature}

Abdizadeh and Baghchesara have studied the optimal melt temperature $\left(750^{\circ} \mathrm{C}-950{ }^{\circ} \mathrm{C}\right)$ for $5-15$ vol. $\%$ of $B_{4} C$ to produce an A356 alloy-based MMC [75]. It was observed that porosity increased alongside melt temperature and reinforcement content. The authors 
show that the inferior mechanical properties at lower temperatures were caused by the higher agglomeration tendency as well as poor wettability. Optimised toughness, elongation, tensile and yield strength were obtained at $850{ }^{\circ} \mathrm{C}$ reinforced with 10 vol.\% $\mathrm{B}_{4} \mathrm{C}$. The best hardness values were shown at highest particle volumetric content and melt temperature from the experiment. Akbari et al. have studied the effects of different particle sizes $(50 \mu \mathrm{m}, 10 \mu \mathrm{m}$ and $20 \mathrm{~nm})$ of $\mathrm{Al}_{2} \mathrm{O}_{3}$ particles at different melt temperature $(750,800$, $950{ }^{\circ} \mathrm{C}$ ) and volumetric content (0.5 to 7 vol.\%) in an A356 alloy [116]. Particles were milled together with $\mathrm{Al}$ powders in a 1:1 weight ratio and introduced through gas injection. Stirring was carried out for $10 \mathrm{~min}$ at $450 \mathrm{rpm}$ before pouring into a steel die, after which samples were heat treated (T6). Porosity is shown to increase with higher volume fractions and smaller sized particles, to which the authors justify with the increase of contact surface area and particle agglomerate (i.e., entrapped gas). For a 1.5 vol. \% content, porosity aggravates at higher melt temperatures, especially for nanoparticles. Results report an optimum volume fraction of $1.5 \mathrm{vol} . \%$ for tensile properties and $2.5 \mathrm{vol} . \%$ for hardness for nanoparticles. For microparticles, the optimised volume fraction is in the range between 3 and 5 vol.\%. Gurusamy et al. have studied the effect of melt and die temperature on the reinforcement of $10 \mathrm{vol} . \% \mathrm{SiC}_{\mathrm{p}}$ on an $\mathrm{A} 356$ alloy by squeeze casting [117]. The processing procedure consists of melting the $\mathrm{A} 356$ alloy at $750{ }^{\circ} \mathrm{C}$ in a graphite crucible, followed by the introduction of the preheated reinforcement particles and a stirring period of 10 min before pouring into a preheated die. In this work, the authors have employed a melt temperature of $750-900{ }^{\circ} \mathrm{C}$ for single die temperature $\left(400{ }^{\circ} \mathrm{C}\right)$ and produced samples with die temperatures of $250-400^{\circ} \mathrm{C}$ for a single melt temperature $\left(800^{\circ} \mathrm{C}\right)$. Results show that these parameters had a significant effect on the microstructure and mechanical properties, while the effect on the MMC distribution was minimal. Optimal UTS, impact strength and hardness are achieved at $850^{\circ} \mathrm{C}$ and $350^{\circ} \mathrm{C}$ melt and die temperature, respectively. Abdizadeh et al. has compared the fabrication $\mathrm{A} 356 / \mathrm{MgO}_{\mathrm{np}}$ at different particle content $(1.5,2.5,5 \mathrm{vol} . \%)$ by stir casting and powder metallurgy at different processing temperatures [118]. In the stir casting method, particles wrapped in aluminium foil were introduced in the melt along with Keryolit $\left(\mathrm{Na}_{3} \mathrm{AlF}_{6}\right)$, followed by a stirring period of $14 \mathrm{~min}$ at $420 \mathrm{rpm}$ at melt temperatures $\left(800,850\right.$ and $\left.950{ }^{\circ} \mathrm{C}\right)$ and pouring. In the powder metallurgy method, $\mathrm{MgO}_{\mathrm{p}}$ and $\mathrm{Al}$ powders were mixed in ethanol for $30 \mathrm{~min}$ and dried, followed by uniaxial pressing and sintering at different temperature $(575,600$ and $625^{\circ} \mathrm{C}$ ). Density measurements reported an agreement to calculated density, while powder metallurgy induced cracks and micropores were observed for higher $\mathrm{MgO}$ content. The authors suggest an optimal processing temperature of $625{ }^{\circ} \mathrm{C}$ and $850{ }^{\circ} \mathrm{C}$ for powder metallurgy and stir casting, respectively, for mechanical property enhancement. Stir casting relative shows some benefits in compressive strength and hardness due to lower porosity. Mazahery and Ostadshabani have fabricated $\mathrm{A} 356 / \mathrm{Al}_{2} \mathrm{O}_{3 n p}$ composites with different reinforcement particle content by stir casting at $800{ }^{\circ} \mathrm{C}$ and $900{ }^{\circ} \mathrm{C}$ [119]. $\mathrm{Al}_{2} \mathrm{O}_{3}$ and aluminium particles were ball milled, passed through a mesh screen, cold-pressed (200 MPa) and passed again through a mesh screen. The particle Al powder mixture was combined with $1 \mathrm{wt} . \% \mathrm{Mg}_{\mathrm{p}}$, and packed in the aluminium foil, being added to the melt once the vortex was formed. Stir casting procedure is characterised by the initial heating of the melt at the desired temperature under protective Argon gas, followed by a stirring period of $15 \mathrm{~min}$ at $600 \mathrm{rpm}$ and finishing by pouring into preheating steel die. Samples microstructure displays uniform distribution of particles with residual agglomeration. Grain refinement is evident in all samples, particularly for 1.5 and 2.5 vol. \%, in which the highest values of tensile and compressive strength were obtained. Although $\mathrm{Al}_{2} \mathrm{O}_{3 n p}$ improved ductility at a melt temperature of $800^{\circ} \mathrm{C}$, the same was verified for $900{ }^{\circ} \mathrm{C}$. The authors suggest that the minimal increase in porosity for greater particle content can be attributed to the reinforcement higher surface area. Shabani et al. have researched the fracture mechanics of 1.8 wt. \% A356/ $\mathrm{Al}_{2} \mathrm{O}_{3 \mathrm{np}}$ composites produced by gravity sand casting, squeeze casting and compo casting [120]. $\mathrm{Al}_{2} \mathrm{O}_{3}$ particles were milled with $\mathrm{Mg}$ and $\mathrm{Al}$ to promote wettability (1:1:2 $\left.\mathrm{Al}_{2} \mathrm{O}_{3}: \mathrm{Mg}: \mathrm{Al}\right)$ and pressed as tablets. Sand casting and squeeze casting were stirred 
at $720{ }^{\circ} \mathrm{C}$ melt temperature for $7 \mathrm{~min}$ before pouring and pressing with a $50 \mathrm{~kg}$ weight. For compo-casting, materials were initially melted at $720^{\circ} \mathrm{C}$ and cooled down to $612{ }^{\circ} \mathrm{C}$ and magnetically stirred for $7 \mathrm{~min}$ before being poured into a steel mould and pressed with a $50 \mathrm{~kg}$ weight. Compared to sand casting, dimples observed in squeeze casting fractography were smaller and more homogenous. It is reported severe agglomeration in the sand casting samples, whereas the pressurised methods are shown to have broken dendrites and dispersed more homogeneously. The authors conclude that smaller and uniformly distributed silicon mitigate the stress concentration, thus enhancing the ultimate strength.

\subsubsection{Wetting Agent}

A wetting agent is considered an additive that can be applied to the reinforcement or melt to enhance the chemical bonding between the two phases and overcome the capillary forces that lead to non-wetting scenarios [50,84,121].

Singh et al. have studied the effects of a Mg wetting agent on the mechanical and thermal properties of an $\mathrm{Al} / \mathrm{SiC}_{\mathrm{p}}$ composite [84]. Results report small changes in the melting point and heat fusion resulting from the introduction of ceramic particles. There is an improvement in tensile strength and hardness at cost of elongation as the weight fraction of the reinforcing phase is increased. The authors state that $\mathrm{Mg}$ acts as surfactant by consuming oxygen from $\mathrm{SiO}_{2}$ and forming $\mathrm{MgO}$ and $\mathrm{MgAl}_{2} \mathrm{O}_{3}$. Despite the strengthening effect, the decrease in melt fluidity by the introduction of $\mathrm{Mg}$ element promotes clustering in contents higher than $15 \mathrm{wt} . \%$. Without $\mathrm{Mg}$, suboptimal tensile strength is reported past $25 \mathrm{wt} . \%$ in which the differences were pointed to the brittleness of the microstructure phase. Tahamtan et al. have studied the effects of introducing ceramic particles in composite particles for 5 vol. \% of $\mathrm{Al}_{2} \mathrm{O}_{3 \mathrm{np}}$ and $\mathrm{Al}_{2} \mathrm{O}_{3 \mathrm{mp}}$ [65]. Reinforcement particles were processed through ball milling the $\mathrm{Al}_{2} \mathrm{O}_{3}$ with $\mathrm{Al}$ and $\mathrm{Mg}$ powders, after which, some were coldpressed into tablets at $1 \mathrm{MPa}$. Stir casting was carried out at 400 and $1200 \mathrm{rpm}$ for $15-30 \mathrm{~min}$ at $745^{\circ} \mathrm{C}$ for the liquid method and $640{ }^{\circ} \mathrm{C}$ for the semi-solid method. As seen from the tensile properties, either form of the composite particles was proved as an effective measure to improve wettability as well as achieve a uniform distribution. The decrease in particle size and stirring temperature is reported as a great improvement as there is less interfacial reaction and the dendrites in the semi-solid state are fractured by the vortex. Su et al. has manufactured an 2024 alloy reinforced with $0.6 \mathrm{wt} . \% \mathrm{Al}_{2} \mathrm{O}_{3}$ along with $\mathrm{Al}$ powder as a carrier agent [122]. With an average diameter of $13 \mathrm{~nm}$ and $80-100 \mu \mathrm{m}$ for $\mathrm{Al}_{2} \mathrm{O}_{3 \mathrm{p}}$ and $\mathrm{Al}_{\mathrm{p}}$ at a 9:1 wt.\% ratio, respectively, particles were introduced into the melt and stirred for $10 \mathrm{~min}$ before pouring. The authors state that the carrier agent establishes a pre-dispersed state which later enhances the wettability between the metal and nanoparticles. Compared with the traditional stir casting, the employed method enhanced UTS, YS and hardness by $59 \%$, $58 \%$ and $16 \%$, respectively. Mousavian et al. has manufactured composite SiC-reinforced aluminium MMC milled with $\mathrm{Cr}, \mathrm{Cu}$ and Ti by stir casting followed by hot extrusion [123]. In this work, mixed particles were encapsulated in aluminium foil packets before their introduction in the melt. Additionally, the authors refer additives as carrier agents given their functionalities in wetting prevent particle agglomeration. Even so, segregation and agglomeration could not be avoided. $\mathrm{Cr}$ and $\mathrm{Cu}$ reported as unsuitable for mechanical property enhancement and it was reported that $(\mathrm{SiC} / \mathrm{Ti})_{\mathrm{p}}$ was successful in reinforcing the matrix with good distribution. The authors show that particle size, process temperature and stirring time limit the manufacturing efficacy. Samiee et al. has manufactured an $\left(\mathrm{Al} / \mathrm{Al}_{2} \mathrm{O}_{3}\right)_{\mathrm{p}}$ composite from a pure aluminium alloy by stir-casting. In their work, the authors introduced the reinforcement particle through an argon-based injection along with $3 \mathrm{wt} . \% \mathrm{Mg}$ during the stirring stage. It was reported that for extended periods $(10 \mathrm{~h})$ of milling, processed $\left(\mathrm{Al}_{2} \mathrm{O}_{3} / \mathrm{Al}\right)_{\mathrm{p}}$ would increase in size and volume, due to collision events and their individual mechanical properties [91]. Akbari et al. have studied the wetting effects of either $\mathrm{Al}$ or $\mathrm{Cu}$ powders on the stir casting of $\mathrm{A356} / \mathrm{Al}_{2} \mathrm{O}_{3 n p}$ [93]. In this work, composite particles were balled milled for different periods (1-24 h), wrapped in aluminium foils and introduced in the vortex. Stirring was performed for $12 \mathrm{~min}$ at 
$450 \mathrm{rpm}$ at $850^{\circ} \mathrm{C}$. After pouring and solidification, the samples were subjected to a T6 heat treatment. The authors report a uniform distribution nanoparticle and reduction in grain size favoured by the ball milling process and mixed powders. With the increase in ball milling time, porosity increased slightly and a general decrease in mechanical properties was observed. The authors suggest that gradual oxidation of the metallic powders may have had a negative impact on the results. The superior mechanical properties reported by the $\mathrm{Al}_{2} \mathrm{O}_{3} / \mathrm{Cu}$ sample were attributed to the strengthening effect of copper in the alloy. Yuan et al. has used squeeze casting to reinforce an $\mathrm{A} 356$ alloy with $(\mathrm{SiC} / \mathrm{Al})_{\mathrm{p}}$ [124]. While performing a stirring period of $10 \mathrm{~min}$ at $180 \mathrm{rpm}$, the authors state that when the size of the composite powder is too small, the stirring stage will not disperse the particle as efficiently as expected, which will then result in agglomeration. Amirkhanlou and Niroumand have studied the effect of aluminium powder with reinforcement particles by the stir casting and compo-casting to obtain $\mathrm{A} 356 / \mathrm{SiC}_{\mathrm{p}}$ composites [125]. ( $\left.\mathrm{SiC} / \mathrm{Al}\right)_{\mathrm{p}}$ was processed through a $52 \mathrm{~h}$ low energy ball milling and later injected into the melt by means of Argon gas as a carrier agent. After a melt homogenization period of $2 \mathrm{~min}$ at $700{ }^{\circ} \mathrm{C}$, particles were injected along with a stirring stage at $500 \mathrm{rpm}$. The stirring period lasted until the desired temperature of $607^{\circ} \mathrm{C}$ (compo-casting) or $650{ }^{\circ} \mathrm{C}$ (stir casting) was reached. The authors report that the injection of a composite powder decreases the overall porosity, promotes homogeneous distribution, and enhances wettability. Compo-casting was shown to further reduce porosity and enhance hardness relatively to the other approaches.

\subsubsection{Additives}

Alternatively, authors have explored the innate wetting effects of direct melt additives to develop sustainable solutions. Early publications report on the wetting effects of $\mathrm{Mg}, \mathrm{Cu}$ and $\mathrm{Si}$ alloying elements, by that order, through the contact angle between $\mathrm{Al}$ and $\mathrm{Be}, \mathrm{B}_{4} \mathrm{C}$, and graphite [126].

Zheng et al. have studied the effect of stirring time in the microstructure and dispersion of $\mathrm{B}_{4} \mathrm{C}$-reinforced aluminium with the use of a Ti additive [94]. The authors report that introduction of the $\mathrm{Ti}$ in melt promotes the growth of $\mathrm{Al}_{3} \mathrm{Ti}$ films in the surface of the particle, thus, limiting the erosion reactions within a 5 min stirring time. Furthermore, it is stated that its particle incorporation threshold (16 vol.\% average) is achieved for stirring periods greater than $20 \mathrm{~min}$. However, for longer holding and stirring time, the $\mathrm{Al}_{3} \mathrm{Ti}$ phase will decompose into $\mathrm{Al}_{3} \mathrm{BC}, \mathrm{AlB}_{2}$ and $\mathrm{TiB}_{2}$, with this last one growing courser and detaching from the $\mathrm{B}_{4} \mathrm{C}_{\mathrm{p}}$. Shahriyari et al. have fabricated Al-based MMC by incorporating $\left(\mathrm{Al}_{2} \mathrm{O}_{3 \mathrm{np}} / \mathrm{Cu}_{\mathrm{mp}}\right)_{\mathrm{p}}$ and studied the effect of a $\mathrm{Sr}$ as an additive in its microstructure and mechanical properties [127]. The authors report that at optimum $0.5 \mathrm{wt} . \%$ strontium, a refining effect can be observed as well as the morphological spheroidization of the Si phase. Higher content will lead to the formation of $\mathrm{Al}_{2} \mathrm{Si}_{2} \mathrm{Sr}$, which, along with a brittle copper phase, will have a negative impact on its mechanical properties. It is suggested that the increase in wettability is promoted by a transition layer or a protective oxide layer in the particle/matrix interface. Mohammadpour et al. have studied the effect of introducing $1 \mathrm{wt} . \% \mathrm{Ca}, \mathrm{Mg}, \mathrm{Si}$, $\mathrm{Ti}, \mathrm{Zn}$ and $\mathrm{Zr}$ alloying elements in the incorporation of $3 \mathrm{wt} . \% \mathrm{SiC}_{\mathrm{mp}}$ in pure aluminium melt [87]. Particles were wrapped in aluminium foil and added to the centre of the vortex. Stir casting was carried out at $500 \mathrm{rpm}$, at a melt temperature of $680{ }^{\circ} \mathrm{C}$ for a period of 6 min, after which the melt was poured into a steel mould preheated at $450{ }^{\circ} \mathrm{C}$. For an introduction of approximately $2.53 \mathrm{vol} . \%, \mathrm{Mg}(2.46 \mathrm{vol} . \%)$ and $\mathrm{Ca}(1.92 \mathrm{vol} . \%)$ stand as the most effective element on particle incorporation followed by the less efficient $\mathrm{Si}, \mathrm{Zn}$ and $\mathrm{Zr}$, in that order. Among the alloying elements, samples contacting $\mathrm{Ti}$ and $\mathrm{Zr}$ substantially increase in microhardeness as a result of the formation of secondary phases $\left(\mathrm{Al}_{3} \mathrm{Ti}\right.$ and $\mathrm{Al}_{3} \mathrm{Zr}$ ). Panthglin et al. have studied the effect of $\mathrm{Zr}$ additives on an A356-SiC composite without resorting to $\mathrm{Mg}$ wetting agents [88]. The addition of $0.2-0.9 \mathrm{wt} . \%$ refined the microstructure and refine the grain by $61-63 \%$ when compared to the $54 \%$ of the Al-5Ti-B master alloy. The introduction of this additive further improved particle incorporation 
as well as promoted a uniform distribution of the $\mathrm{SiC}_{\mathrm{p}}$. Additionally, $\mathrm{Zr}$ enhanced the mechanical properties, such as creep resistance, hardness and microhardness.

\subsubsection{Carrier Agent}

Additionally, the method on how the reinforcement particles are introduced is also considered an important variable that impacts the chemical bonding with the matrix. Given the popularity of the stir-casting process, most authors usually introduce the preheated particles wrapped in aluminium foil [93,128-132] in the centre of an already formed vortex $[68,75,79,82,90]$.

Ghandvar et al. have studied the impact of different steps in particle pre-processing on the reinforcement of $20 \mathrm{wt} . \% \mathrm{SiC}_{\mathrm{p}}$ in an A356 alloy [105]. Samples include untreated particles, particles cleaned in acetone and ultrasonic bath followed by a $900{ }^{\circ} \mathrm{C}(2 \mathrm{~h})$ heat treatment and a separate set of clean and heat-treated particles that was mixed with $1 \mathrm{wt} . \%$ $\mathrm{Mg}$ and packed together in aluminium foil. The authors report that each pre-processing stage produced a significant increase in the composite mechanical properties. The superior wettability between ceramic reinforcements and matrix is justified by the addition of $\mathrm{Mg}$ in aluminium foil. Samal et al. proposed a hollow spindle-stirring mechanism as an alternative for the introduction of particles in the vortex [133]. It is explained that by using a plunger rod with a mild-steel capsule at one end, particles can be directly introduced to the inner regions of the melt. For purposes of experimental validation, the authors reinforced an Al-Mg alloy with $10 \mathrm{wt} . \% \mathrm{SiC}$. Particles were wrapped in aluminium foil and plunged to $800{ }^{\circ} \mathrm{C}$ melt and followed by a $10 \mathrm{~min}$ stirring period at $500 \mathrm{rpm}$. From the resulting microstructure and hardness at different positions, the authors concluded that particles incorporated settled mostly in the middle and bottom section of the cast. Hanizam et al. have studied the effects of mechanical stirring and heat treatment on thixoformed A356 alloy reinforced with $0.5 \mathrm{wt} . \%$ multiwalled carbon nanotubes (MWCNT) [128]. Nanotubes were mixed with $0.5 \mathrm{wt} . \% \mathrm{Mg}$ and wrapped in aluminium foil. After melting at $700{ }^{\circ} \mathrm{C}$, the temperature was lowered to $650{ }^{\circ} \mathrm{C}$ for particle introduction. Similar to the previous authors, the wrapped MWCNTs were placed in the melt through a plunge. With a distinct three-bladed impeller, the melt was mixed at $500 \mathrm{rpm}$ for $10 \mathrm{~min}$ and then poured to a preheated mould $\left(150{ }^{\circ} \mathrm{C}\right)$. Afterwards, the sample was thixoformed at $580^{\circ} \mathrm{C}$, followed by a T6 heat treatment. Despite the stir-casting sample reported a $14 \%$ volume porosity, a gain in ultimate tensile strength, elongation and hardness is also verified with no brittle behaviour. Amirkhanlou and Niroumand have produced $\mathrm{A} 356 / \mathrm{SiC}_{\mathrm{p}}$ through stir-casting and compo-casting [82]. MMC processing includes the injection of either $\mathrm{SiC}_{\mathrm{p}},\left(\mathrm{SiC}_{\mathrm{p}} / \mathrm{Al}\right)_{\mathrm{p}}$ or $\left(\mathrm{SiC}_{\mathrm{p}} / \mathrm{Al} / \mathrm{Mg}\right)_{\mathrm{p}}$ assisted by pressurised argon at $700{ }^{\circ} \mathrm{C}$, followed by a cooling and stirring period up until the melt temperature of $650{ }^{\circ} \mathrm{C}$ or $607^{\circ} \mathrm{C}$, after which the cast was poured into the mould. The authors state that the injection of the reinforcement particles has enhanced the particle distribution and helped minimise the cluster agglomeration. With each reinforcement particle employed, a reduction of the $\mathrm{SiC}_{\mathrm{p}}$ average diameter, secondary dendrite arm spacing and grain size through image analysis. Compo-casting was reported to display enhanced mechanical properties, despite both values had a similar impact on the $\mathrm{SiC}$ particle size. Prakash et al. have studied the effects of particle feeding techniques on the microstructure and mechanical properties of a $2.5 \mathrm{wt} . \% 7075 / \mathrm{Al}_{2} \mathrm{O}_{3 \mathrm{np}}$ by bottom tapping stir casting [134]. In this work feed techniques include (i) regular feeding, (ii) two-step feeding, (iii) pre-melt feeding, (iv) capsulate feeding and (v) double-layer feeding, which are then followed by a stirring period and pouring. Regular feeding refers to the introduction of the particles in a static melt. Two-step feeding consists of the regular method of half the melt charge and particle content followed by the charging of the remaining aluminium charge and reinforcement content. The pre-melt method is described as the charging of the two materials in the crucible to melt together. Capsulate feeding consists of the packaging of the reinforcement particles in aluminium foil to be later pre-heated at $300{ }^{\circ} \mathrm{C}$ and added to the melt. Similar to the pre-melt method, particles are loaded into the furnace between two layers of aluminium charges. The three first techniques employed 
(i-iii) report high levels of porosity, an agglomeration tendency and failure to incorporate the matrix as a considerable percentage of the particles are found at the metal surface. Optimal mechanical properties and particles distribution are achieved by double-layer and capsulate feeding, in that order, given that the last reports some agglomeration and higher porosity.

\subsubsection{Melt Additives}

The combination of multi-parameter processes comprising the introduction of an additive can frequently overlap the effects promoted by reinforcement particle pre-processing and have a significant impact on the final MMC mechanical properties. Considering that the incorporation of particles is widely recognised for refining effect, the use of grain refiners along with ceramic reinforcements is not a common procedure considering that it may be redundant.

Suresh et al. have studied the effect of a commercial Al-Ti-B master alloy and flux modifier in the reinforcement of 1-15 wt.\% fly ash in eutectic Al-12Si alloy [135]. The authors report an increase in hardness, ultimate tensile strength and elongation in additions up to $10 \mathrm{wt} . \%$. For higher mass fractions, both tensile strength and hardness tend to decrease, while elongation only decreases past $15 \mathrm{wt} . \%$. Optimum results are achieved by samples with grain refiner, that may hinder increases of $48 \%, 58 \%$ and $5 \%$, respectively, in hardness, tensile strength and elongation. The use of the flux modifier, either isolated or complemented with the grain refiner, is reported to enhance the same properties, however, still lower than the grain refiner approach. Toptan et al. have fabricated $A 1070 / B_{4} C_{p}$ and $\mathrm{A} 6063 / \mathrm{B}_{4} \mathrm{C}_{\mathrm{p}}$ through traditional casting and T6 heat treatment. To overcome particlematrix wettability problems, the author added $\mathrm{K}_{2} \mathrm{TiF}_{6}$ flux [136]. Results show an improved particle wettability as the flux induces the formation of $\mathrm{TiC}$ and $\mathrm{TiB}_{2}$ layer in the $\mathrm{B}_{4} \mathrm{C}$ interface. The formation of this reaction layer denotes no significant changes for either alloy, as-cast or T6 heat treated sample. Kalaiselvan et al. have reinforced A6063 with 4 to 12 vol.\% of $\mathrm{B}_{4} \mathrm{C}$ by stir casting with the use of $\mathrm{K}_{2} \mathrm{TiF}_{6}$ flux as a wetting agent [137]. Processing procedure consists of an initial melt of the alloy at $920{ }^{\circ} \mathrm{C}$ under an inert Argon atmosphere, followed by a stirring period of $5 \mathrm{~min}$ at $300 \mathrm{rpm}$. Particles preheated at $400{ }^{\circ} \mathrm{C}$ and $\mathrm{K}_{2} \mathrm{TiF}_{6}$ flux were introduced into the vortex at a $0.8-1.2 \mathrm{~g} / \mathrm{s}$ feed rate. The authors report an improvement in $\mathrm{B}_{4} \mathrm{C}$ wettability as the flux reacts with the melt inducing the formation of Ti compounds at the particle's surface. Results display a linear improvement of the ultimate tensile strength, microhardness and macrohardness for every particle amount.

This is in agreement with other published work $[94,129,138,139]$, as authors use either $\mathrm{K}_{2} \mathrm{TiF}_{6}$ flux or Al-Ti-B master alloys to promote the interfacial Ti compounds in $\mathrm{B}_{4} \mathrm{C}$ particles surface. Other fluxes such as Cryolite $\left(\mathrm{Na}_{3} \mathrm{AlF}_{6}\right)[78,140]$ and others are employed to improve casting quality and efficiency rather than particle wettability or distribution. The same can be extended to other casting specific additives, as the hexachloroethane degassing tablets [81,141-143] since no conclusion is derived concerning particle-related issues.

\subsubsection{Other Methods}

Recently, more authors have extended their research to other particles or alternative reinforcement methodologies. Frequently these include multi-sized reinforcement [144-146], in which two different magnitude-sized particles of the same compound are incorporated, or hybrid reinforcement [146-151], in which two chemically distinct particles are introduced.

Adebisi et al. studied the effect of different sized particles and multi-sized particles on the mechanical and tribological properties of $6061 / \mathrm{SiC}_{\mathrm{mp}}$ [144]. The methodology includes charging and complete melting of the $\mathrm{Al}$ alloy as well as the addition of $1 \mathrm{wt} . \% \mathrm{Mg}$. Melt temperature is lowered to a semi-solid state, in which pre-oxidised particles $\left(1200^{\circ} \mathrm{C}\right.$ for $\left.2 \mathrm{~h}\right)$ are incorporated. Afterwards, the melt is heated to $800^{\circ} \mathrm{C}$ and stirred at $500 \mathrm{rpm}$ for $3 \mathrm{~min}$ before pouring into the mould. The authors report an increase in hardness for smaller sized particles, however, best results are presented by the multi-sized particle sample. Superior impact strength is also reported by the multi-sized particle sample followed single- 
sized particle samples from larger to smaller. The authors attribute multi-sized particle tribological performance to its superior load-bearing capacity. Lakshmikanthan et al. have studied the effect of the incorporation of dual sized SiC particles in the microstructure, mechanical and wear properties of an A357 composite [152]. Particles of $140 \pm 10 \mu \mathrm{m}$ and $30 \pm 5 \mu \mathrm{m}$ size were configured in three different sets at a total $6 \mathrm{wt} . \% \mathrm{SiC}$. Melt was initially stirred at $550 \mathrm{rpm}$ and degassed with Hexachloroethane tablets. After lowering stirring speed to $300 \mathrm{rpm}$, preheating particles $\left(1100{ }^{\circ} \mathrm{C}\right.$ for $2 \mathrm{~h}$ ) were incorporated in the melt and stirred for $15 \mathrm{~min}$ until pouring into a steel mould. Composite favouring large-sized particles (4 wt. $\% 140 \mu \mathrm{m}+2 \mathrm{wt} . \% 30 \mu \mathrm{m} \mathrm{SiC}$ ) obtained the highest hardness values, while superior tensile properties were reported for the finer-sized particles $(2 \mathrm{wt} . \%$ $140 \mu \mathrm{m}+4 \mathrm{wt} . \% 30 \mu \mathrm{m} \mathrm{SiC}$ ). The authors infer that the smaller particles were responsible for grain refinement and dislocation strengthening, while larger sized particles induced a greater load-bearing effect. Wear resistance was found to be correlated best with loadbearing capacity, thus encouraging larger sized particles. Kumar et al. have produced an A356 alloy reinforced with $\mathrm{Al}_{2} \mathrm{O}_{3} / \mathrm{SiC} / \mathrm{Gr}$ through squeeze casting and studied its effect on mechanical properties [153]. In this work, 1 to $5 \mathrm{wt} . \%$ of each of particles (preheated at $450{ }^{\circ} \mathrm{C}$ ) along with $1 \mathrm{wt} . \% \mathrm{Mg}$ were introduced in the melt at $750{ }^{\circ} \mathrm{C}$, which was then stirred at $250 \mathrm{rpm}$ for $10 \mathrm{~min}$. Afterwards, molten aluminium was poured into the hydraulic plunger with an applied pressure of $100 \mathrm{MPa}$ for a period of $30 \mathrm{~s}$ and later the cast samples were subjected to a T6 heat treatment. Results show an increase in hardness and tensile strength up to $3 \mathrm{wt} . \%$ individual particle content, after which these properties tend to decrease. The authors report a reduction in elongation with higher reinforcement volume fraction. Ghanaraja et al. have manufactured aluminium composite with different sized $\mathrm{MnO}_{2 \mathrm{p}}$ through stir casting [154]. Along with a $5 \mathrm{wt} . \% \mathrm{Mg}$ wetting agent, particles were introduced and stirred with a coated steel two-stage impeller. The generation of nanosized $\mathrm{Al}_{2} \mathrm{O}_{3}$ is suggested to have been generated during the milling stage, while larger particles are originated during melt processing. It is reported that the higher content of smaller particles tends to have higher ductility when compared with larger particles at lower content. Although higher reinforcement content leads to higher ductility, yield and ultimate tensile strength, these gains cease after $3 \mathrm{wt} . \%$ given the tendency to form clusters. Gayathri and Elansezhian studied the effect of different $\mathrm{CuO}_{n p}$ content along with spent $\mathrm{Al}_{2} \mathrm{O}_{3}$ catalyst in the microstructure and mechanical properties of a hybrid LM25 alloy-based composite [146]. A 10 vol. $\%$ of $20 \mu \mathrm{m} \mathrm{Al}{ }_{2} \mathrm{O}_{3}$ was preheated at $500{ }^{\circ} \mathrm{C}$ for $3 \mathrm{~h}$, while 0.5 to $1 \mathrm{vol} . \% 40 \mathrm{~nm} \mathrm{CuO}$ were preheated at $750{ }^{\circ} \mathrm{C}$ for $6 \mathrm{~h}$. After initial melting at $750{ }^{\circ} \mathrm{C}$, the melt was cooled to $580{ }^{\circ} \mathrm{C}$ for the addition of spent $\mathrm{Al}_{2} \mathrm{O}_{3}$ and stirred at $350 \mathrm{rpm}$ for $10 \mathrm{~min}$. Afterwards, the mixture was heated to $650{ }^{\circ} \mathrm{C}$ and stirred at $500 \mathrm{rpm}$ for $10 \mathrm{~min}$. Results report no agglomeration among the tested samples. It is reported a linear gain in hardness and tensile properties along with the increase in $\mathrm{CuO}$ content. The authors propose the $\mathrm{Cu}$ phase precipitates in the inter-dendrite region and, thus, enhance the mechanical properties. Elshalakany et al. have studied the effect of wt.\% content of multiwalled carbon nanotubes (MWCNT) on an A356 alloy-based composite produced through hybrid rheocasting and squeeze casting [143]. In this work, MWCNT is mixed with $\mathrm{Al}_{\mathrm{p}}$ to form a composite billet through a low temperature compression for the introduction. A356 alloy was melted at $660^{\circ} \mathrm{C}$, degassed with hexachloroethane and protected with Argon gas. After cooling down to $601^{\circ} \mathrm{C}, 0.75 \mathrm{wt} . \% \mathrm{Mg}$ and reinforcements were introduced in the semisolid state and stirred for $1 \mathrm{~min}$ at $750 \mathrm{rpm}$ until pouring and squeezing. The authors state that all samples achieve a homogenised distribution without the precipitation of new phases. A 50\% and $60 \%$ improvement on UTS and YS for optimum content of $1.5 \mathrm{wt} . \%$, while for compressive strength this was verified at $1 \mathrm{wt} . \%$ A356/MWCNT, which was related to lack of wettability and agglomeration. In contrast, hardness was improved up to $88 \mathrm{HRB}$ to the maximum content tested (2.5 wt.\%). 


\subsubsection{Stir Casting}

With the incorporation of heterogeneous particles in the melt, the fluid's flow and heat transfer characteristics are altered which then influence the distribution and agglomeration of the particles. Karantzalis et al. have reported that even if the reinforcement particles are well distributed and wetted in the melt, the difference in thermal conductivity between the reinforcement and the matrix move the particle's position during solidification [155]. Mousavian et al. have verified in their work that even though a post-cast extrusion has modified the microstructure of the samples through deformation, the distribution of the nano or microparticles did not change [123]. In squeeze casting and similar processes, parameters (squeeze pressure and holding time) hold a greater impact on the materials properties rather than melt or mould temperature. Even so, the authors have stated that melt stirring overlaps its own function as it delays the particle settling before solidification [156]. In order to improve MMC casting typical problems, the authors have procured several methods to successfully disperse and/or de-agglomerate particles in the melt. Among them, the stir casting and ultrasonic melt treatment present themselves as common manufacturing options in the literature [128,142,157-163]. However, it is yet a processing path difficult to be summarised by a generalised guideline. Although it is stated that mechanical stirring enhances the particle's wettability, there is also a benefit by decreasing the stirring speed in the introduction as it avoids the projection of low-density particles during high shearing flows [145]. As verified by several authors, the average dispersion of reinforcement particles tends to be more effective and efficient for smaller size particles, which also tends to produce superior mechanical properties [77,92]. Figure 4 summarises the impact of differing stirring speeds and periods of distinct sized particles on $<5$ vol. $\%$ composite relying only on stir casting as reported by several authors. Even though the two bar plots suggest an optimal value for each particle type and size, it should be noted that mechanical properties are still subjected to other treatments whose influence is evidenced by the standard deviation between parameter values. Therefore, appropriate selection of stirring parameters is imperative, and yet subjective, as the different particles size and density as well as pre-heating and melt temperature can interfere in its successful dispersion, unavoidably, their material properties.
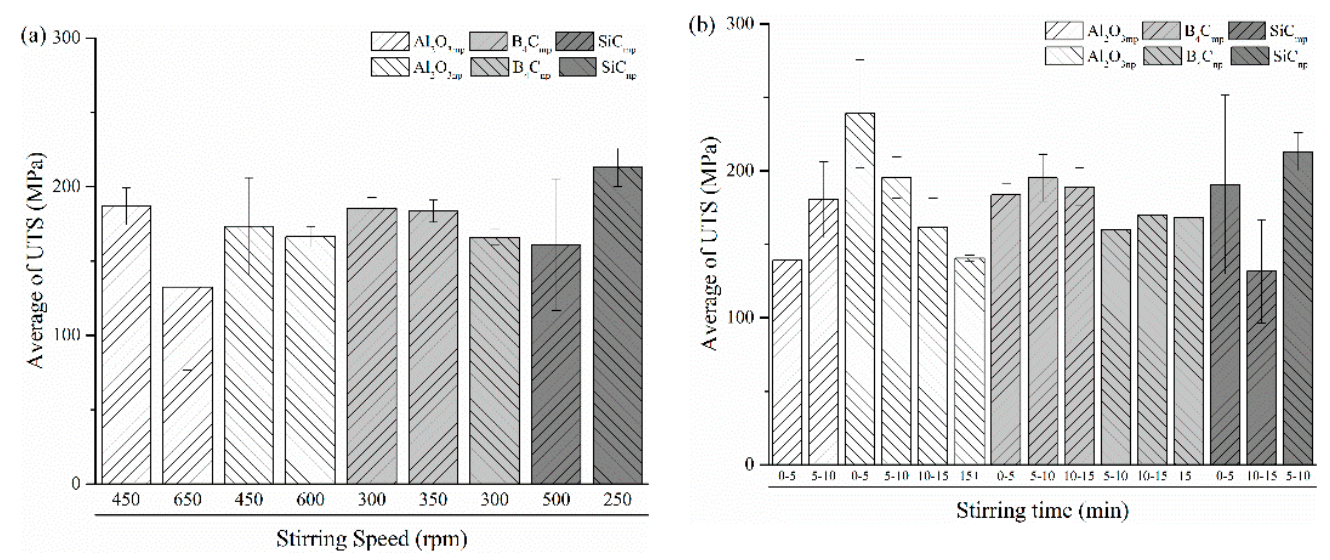

Figure 4. Ultimate tensile strength in function of stirring period, particle type and size for $<5$ vol. $\%$ MMC. (a) Stirring speed; (b) Stirring time. Refs [10,75,76,78,79,82,95,119,123,127,164,165].

Akbari et al. have studied the impact of different periods of stirring on the distribution of $\mathrm{Al}_{2} \mathrm{O}_{3 \mathrm{np}}$ milled together with $\mathrm{Al}$ or $\mathrm{Cu}$ powders in an $\mathrm{A} 356$ melt [166]. Nanoparticles are ball milled with $\mathrm{Al}$ or $\mathrm{Cu}$ powders in a 1:1 mass ratio and later wrapped in aluminium foil. Melt is heated to $850{ }^{\circ} \mathrm{C}$ and stirred using a graphite system at $450 \mathrm{rpm}$ for 4, 8, 12, and $16 \mathrm{~min}$. After pouring into a steel mould, samples were subjected a T6 heat treatment. Micrographs depict some cases of agglomeration, particularly in the lower section of the mould. The authors report that porosity levels increased with the volume fraction of reinforcement particles and for longer periods of stirring on all samples. Even 
though, optimal hardness and compressive strength, as well as minimum wear rate, were achieved for the $\left(\mathrm{Al}_{2} \mathrm{O}_{3 \mathrm{np}} / \mathrm{Cu}\right)_{\mathrm{p}}$ sample after stirring of $4 \mathrm{~min}$. Despite the effect of porosity, the authors attribute the relative mechanical performance to the strengthening factor and distribution of the $\mathrm{Cu}$ powders. Shirvanimoghaddam et al. have studied the mechanical and physical properties of an $\mathrm{A} 356 / \mathrm{B}_{4} \mathrm{C}$ composites fabricated by stir casting with different volume fractions and melt temperatures. Further, the authors use their results to train neural networks for two different models to predict hardness and tensile strength [78]. The manufacturing procedure consisted in an initial melting of A356 ingot and introduction of $10 \mathrm{~g}$ Cryolite $\left(\mathrm{Na}_{3} \mathrm{AlF}_{6}\right)$, followed by a stirring with a four-bladed $45^{\circ}$ angled graphite impeller at $350-400 \mathrm{rpm}$ at a melt temperature of $800{ }^{\circ} \mathrm{C}$ or $1000^{\circ} \mathrm{C}$. Particles were packed in aluminium foil and introduced into the melt in the stirring stage for 4 to $12 \mathrm{~min}$ with a 5 to $15 \mathrm{vol} \% \mathrm{~B}_{4} \mathrm{C}$ content. The authors report an increase in wettability and mechanical properties for higher melt temperatures. Additionally, it is stated that a shorter stirring time will cause a non-uniform distribution, while for longer periods, particles tend to be projected and agglomerate in the sides of the crucible. Comparison between the experimental data and the data from the neural network revealed accurate and low errors. Lakshmikanthan et al. have studied the effects of artificial ageing temperature and particle size ratio on a double particle size $\mathrm{SiC}_{\mathrm{mp}}$ reinforced $\mathrm{A} 357$ composite [145]. This procedure consisted in a two-step stirring: (i) first in the raw melt was stirred at 550-600 rpm; and (ii) and the second consisted in the addition of particles at stirring speed of $300 \mathrm{rpm}$. Cast samples were finally subjected to a T6 heat treatment. Although most samples report a good distribution with a small cases of nanoparticle clustering, best distribution was achieved with $2 \mathrm{wt} . \%$ coarse and $4 \mathrm{wt} . \%$ fine particles. The authors advise that a careful selection of stirring speed needs to be taken with caution for smaller particles as it transports in relative higher momentum in the direction of the flow. It is further shown that in high shear melt flows, smaller particle velocity is restricted by larger particles, eventually settling in their vicinity. Chen et al. have studied the particle trajectory of $\mathrm{SiC}$ particles in the A356 melt during casting through numerical analysis and experimental data, in which filling was observed by X-ray radiography and a highspeed camera [142]. During pouring, it is reported that the particle fractions decrease for longer fluid trajectories. A relative lower particle volume fraction was reported at the surface of the cast component, to which authors have hypothesised this to be promoted by the primary $\alpha-\mathrm{Al}$ pushing particles to its inner region as a result of its solidification mechanism. In a laminar flow regime, particles tend move to near-wall regions, while for turbulent flows particle trajectory is mostly dictated by eddy flow and wall collision. Sahu and Sahu have studied the flow behaviour of the melt stirring $\mathrm{B}_{4} \mathrm{C}$ and Fly-ash particles in an Al 7075 melt through numerical simulation and optimised its parameters for particle distribution and minimise stagnant/dead zones [138]. The authors suggested a blade angle of $30^{\circ}$, impeller with a diameter that corresponds to the crucible radius and stirring speed $550 \mathrm{rpm}$ for optimal stir casting under the studied conditions. Through Grey relational grade, it is reported that the mitigation of dead zones is influenced by impeller size, blade angle and stirring speed, in this order. Su et al. have studied the effect of melt flow behaviour on the distribution of the particles in the stir casting process through numeric simulation [167]. Resorting to the finite element method, the authors studied the impact of stirring-related parameters such as the blade angle, rotating speed, the diameter of the impeller, and the stirrer geometry on the effective flow parameter. The authors suggested using a multistage stirrer and high stirring speeds to obtain optimal processing conditions, showing that stagnant regions and dead zones in the crucible could be minimised. Considering that a high angle blades induce shearing flow, lower angles are preferable for particle incorporation. The author state that an increase of impeller diameter/crucible diameter ratio from 0.25 to 0.55 has a significant impact on particle distribution. However, for higher ratio, axial flows increase which then leads to excessive turbulence. Numerical results were later validated empirically for stirring speed, being concluded that the best distribution was achieved for $1000 \mathrm{rpm}$ promoting particle cluster 
deagglomeration. Li et al. has studied the effect of the dynamically liquid-stirring periods on the resulting microstructures, and particles dispersion [94]. The authors show that the shearing and turbulent melt flow is capable of deagglomeration and dispersing $\mathrm{B}_{4} \mathrm{C}$ particles to sufficient state for $20 \mathrm{~min}$, but a fully randomised dispersion was observed at $55 \mathrm{~min}$. It is stated that for $\mathrm{B}_{4} \mathrm{C}$, sedimentation and buoyancy effects can be ignored given the close density between the particle and the aluminium melt.

Although the method is not common, some authors have adopted a dynamic melt temperature cycle in their processing, often labelled as two-stage stir casting. The methodology can be described as an initial melting, followed by a simultaneous cooling and stirring stage at a lower temperature (liquidus $[77,124,160]$ or semi-solid $[129,142])$. Afterwards, the melt was superheated to the designated pouring temperature (above liquidus) and held for a specific amount of time before pouring. As the particles immersion time and melt temperature changes between publications, it can be difficult to quantify the efficiency of the method relative to others even though its efficacy is reported and verified. Wu et al. processed $\mathrm{A} 356 / \mathrm{SiC}_{\mathrm{np}}$ by stir casting and ultrasonic treatment (UST) [160]. SiC particles were oxidised at $850{ }^{\circ} \mathrm{C}$ for $2 \mathrm{~h}$ and mixed with aluminium powders through high energy ball milling. After the alloy melts, it was cooled down to $680^{\circ} \mathrm{C}$, at which the preheated particles $\left(250{ }^{\circ} \mathrm{C}\right)$ were introduced into the vortex. Stirring proceeded at $250 \mathrm{rpm}$ for $10 \mathrm{~min}$, followed by a melt superheating to $720^{\circ} \mathrm{C}$ and holding for $30 \mathrm{~min}$. Subsequently, UST ( $2.8 \mathrm{~kW}$ at $20 \mathrm{kHz}$ ) was employed for a duration of $3 \mathrm{~min}$. Composite melt was poured into a preheated steel mould $\left(250^{\circ} \mathrm{C}\right)$ and squeeze cast at $60 \mathrm{MPa}$. It is reported that no significant agglomeration was observed, which indicates the benefits of the UST. The authors show that ball milling SiC with the carrier agent allowed a good particle-matrix wettability. Optimal mechanical properties were with $2 \mathrm{wt} . \% \mathrm{SiC}_{\mathrm{np}}$ and no drawback tendency reported. Hu et al. studied the effects of Ti containing powders and fluxes as well as stirring stage temperature in the fabrication of $10 \mathrm{wt} . \% \mathrm{~A} 356 / \mathrm{B}_{4} \mathrm{C}$ [129]. Liquid processing path consisted of an initial stirring at $300 \mathrm{rpm}$ at melt temperature $780{ }^{\circ} \mathrm{C}$ along with the introduction of $1 \mathrm{wt} . \%$ Ti powders wrapped in $\mathrm{Al}$ foil. Afterwards, $\mathrm{B}_{4} \mathrm{C}$ particles are introduced into the vortex and stirred at $450 \mathrm{rpm}$ for $15 \mathrm{~min}$ before the cast samples are quenched in cold water. The semi-solid stirring path consisted of an initial melt of the alloys (A356 and Al-15Ti) at $700{ }^{\circ} \mathrm{C}$, followed by cooling to a semi-solid state $\left(590-610^{\circ} \mathrm{C}\right)$. Subsequently, $\mathrm{B}_{4} \mathrm{C}$ were introduced into the vortex stirred at $350 \mathrm{rpm}$. Melt was then heated to $670{ }^{\circ} \mathrm{C}$ and stirred at $450 \mathrm{rpm}$ for 150 before quenching in cold water. It is reported that the introduction of Ti-containing compounds benefit the distribution as it promotes wetting between the melt and the $\mathrm{B}_{4} \mathrm{C}$, and it later nucleates a layer of $\mathrm{TiB}_{2}$ crystals. The authors justify that the semi-solid stirring enhanced the distribution through the imposed shearing on agglomerated particles, thus inducing deagglomeration and homogenous distribution.

\subsubsection{Other Forms of Stirring}

Although stir casting is commonly performed through impellers as it is the most accessible option, other authors have employed alternative methods of melt agitation [64].

Kaisarlis et al. have produced coal fly ash composites from an A380 alloy by gravity casting [168]. The authors have developed an apparatus based on a high-energy ring-mill pulverizer to produce ultra-fine particle sizes $(<1 \mu \mathrm{m})$. Additionally, an oscillating microgrid melt mixer implemented in a piston-rod assembly is used to impose shearing forces onto the melt with de-agglomeration purposes. With the increase in coal fly ash content up to $10 \mathrm{wt} . \%$, it is reported an enhancement in tensile strength, hardness and wear resistance along with a decrease in ductility and toughness. Lal et al. have characterised the microstructure, thermal and mechanical properties of a $7075 /\left(\mathrm{Al}_{2} \mathrm{O}_{3} / \mathrm{SiC}\right)_{\mathrm{mp}}$ composite [169]. Alloys were charged into the crucible and melted at $715^{\circ} \mathrm{C}$, being degassed for $10 \mathrm{~min}$ with argon. Different particles compositions (5-20 wt.\%) were mixed in a 1:1 ratio and preheated at $900{ }^{\circ} \mathrm{C}$. Afterwards, particles were introduced in the melt through a formed vortex and continuously electromagnetically stirred for $6 \mathrm{~min}$. Cast samples were to cool in the air. The 
authors report uniform and homogeneous distribution in all samples with no formation of $\mathrm{Al}_{4} \mathrm{C}_{3}$ brittle phase. Differential thermal analysis shows a negligible material loss in the composite. Optimised tensile properties were reported for $15 \mathrm{wt} . \%$, while superior hardness was achieved at $20 \mathrm{wt} . \%$. Elongation and impact energy tends to decrease as the reinforcement content increases. Golak and Dyzia developed a form of centrifugal casting with an interior channel of a concrete mould subjected to electromagnetic stirring [170]. Induction coils are positioned inside the mould ( $7 \mathrm{~mm}$ from the wall). $\mathrm{An} \mathrm{AlSi}_{12} \mathrm{CuMg}$ is incorporated with $\mathrm{SiC}_{\mathrm{mp}}$ through stir casting at $720^{\circ} \mathrm{C}$ and poured to a $220^{\circ} \mathrm{C}$ preheated mould. Once the mould is filled, the inductor is activated for $7 \mathrm{~s}$, after which the casting is allowed to cool. From image analysis, the authors report a constant volumetric mean and standard deviation of reinforcement particles up to $4 \mathrm{~mm}$ from the inner wall. Yang et al. have used intensive melt shearing to study the dispersive effect on different sized particles on $\mathrm{A} 356 / \mathrm{SiC}_{\mathrm{p}}$ composite and fluidity tests were performed to attest liquid flow and solidification behaviour [79]. MMC processing consisted of initial heating to $800{ }^{\circ} \mathrm{C}$ to melt the alloy, after which the melt temperature was lowered to $600^{\circ} \mathrm{C}$ in which the particles were introduced. The melt was then stirred by an impeller at $650 \mathrm{rpm}$ for $5 \mathrm{~min}$ followed by a second stirring stage using two distinct approaches: (i) impeller stirring at $650 \mathrm{rpm}$ for $5 \mathrm{~min}$ at $730^{\circ} \mathrm{C}$; or (ii) intensive metal shearing at $5000 \mathrm{rpm}$ for $5 \mathrm{~min}$ at $730^{\circ} \mathrm{C}$. The authors report that the melt shearing processing improves both mechanical and tribological properties when compared to the second step impeller stirring. These gains seem more noticeable for particles size of $4.5 \mu \mathrm{m}$ and $9.5 \mu \mathrm{m}$ rather than $12 \mu \mathrm{m}$. It is hypothesised that these volume fractions promote a reduction in melt viscosity.

\subsubsection{Ultrasonic Melt Treatment}

Ultrasonic melt treatment is a current popular option for its ability to promote grain refinement, equiaxed grains as well as melt degassing [57,171]. The acoustic pressure waves have been reported to be able of fragmenting dendrites and induce a vortex-free flow. The use of the ultrasonic treatment in manufacturing has been reported to transfer its enhanced tensile strength and elongation onto metal matrix composites along with improving the particle's wettability $[160,172,173]$.

Jia et al. have experimented and modelled the effect of ultrasonic cavitation in the production of $6061 \mathrm{MMCs}$ reinforced with $1 \mathrm{wt} . \% \mathrm{Al}_{2} \mathrm{O}_{3}$ or $\mathrm{SiC}$ nanoparticles. Modelling analysis includes a fluid flow and particle distribution during particle injection and the ultrasonic probe is positioned at the bottom or the top of the crucible [174]. Results report a residual change in UTS but significant increase in elongation, which was justified by observation of agglomeration and microporosity. Furthermore, it is suggested that the presence of nanoparticles induce cross slip in non-basal slip planes that may have increased the sample's ductility. The CFD modelling results show no significant improvement in either setup, to which should remain true as long as the flow remains strong enough to disperse the nanoparticles. Jia et al. have experimented and modelled the effect in ultrasonic cavitation in the dispersion of $\mathrm{Al}_{2} \mathrm{O}_{3}$ or $\mathrm{SiC}$ particles in an $\mathrm{A} 356$ melt [83]. The authors report that both $\mathrm{MMC}$ samples promote grain refinement and dendrite fragmentation under ultrasonic treatment. Some minor agglomeration is reported in the numeric and experimental results which could be originated during the ultrasonic processing or solidification. Vorozhtsov et al. have studied the effect of $\mathrm{ScF}_{3 n p}$ on the microstructure and mechanical properties of A356 alloy-based MMC [175]. The introduced reinforcement consists of $20 \mathrm{wt} . \% \mathrm{ScF}_{3 n p}$ mixed with $\mathrm{Al}_{\mathrm{p}}$ and later wrapped in aluminium foil. Melt procedure can be summarised with UST degassing for $1 \mathrm{~min}$ at $760^{\circ} \mathrm{C}$, followed by particle introduction and UST for $2 \mathrm{~min}$ at $720-740^{\circ} \mathrm{C}$, after which, the melt was poured at $710^{\circ} \mathrm{C}$ into a metallic mould. Compared to the as-cast A356 alloy, results report an increase in hardness, UTS, YS and elongation for $0.2 \mathrm{wt} . \%$ but slightly less for $1 \mathrm{wt} . \% \mathrm{ScF}_{3 n p}$. The authors state that the clusters formed along the grain boundaries may have affected the properties of the MMC. Idrisi and Mourad have compared the effects of conventional stir casting and the ultrasonic-assisted stir casting techniques on AA5083/SiC MMC [173]. Re- 
sults show that deployment of the ultrasonic probe enabled the enhancement of composite tensile and compressive strength, hardness as well as the reduction in porosity, particularly for higher weight percentage. Although some clusters were detected, the authors explain that, through the acoustic transient cavitation of microbubbles, clusters are shattered and their gas layer removed, thus, improving the particle/matrix wettability.

\subsubsection{Hybrid Processing Stir}

Authors have stated that UST coupled with mechanical stirring improves the wettability and distribution of the particles reinforcements [68].

Aybarc et al. have studied the effects of a hybrid ultrasonic-assisted stir-casting of $\mathrm{Al}_{2} \mathrm{O}_{3 \mathrm{np}}$ and $\mathrm{Al}_{2} \mathrm{O}_{3 \mathrm{mp}}$ in an $\mathrm{A} 356$ melt [68]. Although reinforcement addition shows an improvement in mechanical properties, the use of lower content of nanoparticles reports the optimal enhancement with minimum porosity percentage. Even so, the authors state that particle size and its higher thermal conductivity play a greater role in grain refinement and porosity mitigation. Yuan et al. have studied the effect of different ultrasonic treatment periods in $\mathrm{A} 356 / \mathrm{SiC}_{\mathrm{np}}$ MMCs processed through squeeze casting [77]. After melting at $720^{\circ} \mathrm{C}$ stirring was performed and particles were introduced in the vortex. The melt was cooled to $680^{\circ} \mathrm{C}$ and continued to be stirred at $180 \mathrm{rpm}$ for $15 \mathrm{~min}$. Afterwards, the melt was superheated to $720^{\circ} \mathrm{C}$, held for $30 \mathrm{~min}$ and degassed for $10 \mathrm{~min}$ with argon gas. Ultrasonic melt treatment $(2.8 \mathrm{~kW}$ at $20 \mathrm{kHz})$ was employed for different time periods $(0.5-5 \mathrm{~min})$ before being poured into a preheated steel die at $250{ }^{\circ} \mathrm{C}$ and squeeze cast. It was reported that its maximum refining effect is achieved at 2-3 $\mathrm{min}$, after which the gains fade for longer treatment time. Although by itself ultrasonic treatment does not significantly reduce secondary dendritic arm spacing, the authors state that the grain refinement effect of the nanoparticles is only noticeable when accompanied by ultrasonic-assisted process. Despite the results, the effects of the UST combined with $\mathrm{SiC}_{\mathrm{np}}$ on the microstructure is not clear as particle distribution are difficult to observe, even though agglomeration is reported. Yuan et al. have produced $(\mathrm{SiC} / \mathrm{Al})_{\mathrm{p}}$ reinforced on $\mathrm{A} 356$ alloy by squeeze casting [124]. After a melting of the alloy at $720^{\circ} \mathrm{C}$, the melt was cooled to $680^{\circ} \mathrm{C}$ and particles were introduced, followed by a stirring period of $10 \mathrm{~min}$ at $180 \mathrm{rpm}$. The melt temperature was superheated to $720^{\circ} \mathrm{C}$ for a holding stage of $30 \mathrm{~min}$, after which the ultrasonic treatment was applied for $3 \mathrm{~min}$ and then poured into the mould. It is reported that at $0.5 \mathrm{wt} . \%$ the reinforcement effect was negligible given the insufficient content for a uniform distribution. The authors state that for 1 and $2 \mathrm{wt} . \%$ residual agglomeration was observed. Li et al. have studied the effect of the period of ultrasonic melt treatment in a $\mathrm{SiC}_{\mathrm{p}}$ in $\mathrm{Al}-5 \mathrm{Cu}$ composite [176]. Composite granules with a size of $1-2 \mathrm{~mm}$ were produced by milling $40 \mathrm{~nm} \mathrm{SiC}_{\mathrm{p}}(6 \mathrm{wt}$.\%) and $30 \mu \mathrm{m} \mathrm{Al}$. Materials were melted at $750{ }^{\circ} \mathrm{C}$, stirred for $10 \mathrm{~min}$ at $120 \mathrm{rpm}$ under a protective atmosphere and later degassed by Argon for $10 \mathrm{~min}$. Afterwards, the melt was poured to a metal cup in a holding furnace for UST at different time periods, after which, it was poured into the mould and squeezed with $50 \mathrm{MPa}$ pressure. The authors have verified that a $1 \mathrm{~min}$ treatment was sufficient for the de-agglomeration into smaller aggregates, however, particles are uniformly dispersed for a $5 \mathrm{~min}$ treatment period. The UST refinement effect on the $\alpha-\mathrm{Al}$ and $\mathrm{Al}_{2} \mathrm{Cu}$ showed no adverse effect for the tested time periods. Furthermore, it is stated that the UST degassing effect enabled the decrease in porosity from $4 \%$ (as-cast MMC) to $0.53 \%$ (UST $5 \mathrm{~min}$ ). Results report a $7.6 \%, 6.8 \%$ and $29 \%$ increase in UTS, YS and elongation for 5 min treatment compared to the as-cast MMC.

\section{Recommendations}

Considering the integrated analysis of this review and the results from these publications that are detailed in the discussion section, the recommended process parameters for stir casting or UST casting for the manufacturing of Al-Si based MMCs are provided in Table 3. 


\subsection{Particle Pre-Processing and Introduction}

As seen previously in Figure 3, a higher particle temperature can lead to an improvement in the particle wettability. However, prolonged exposure to high temperatures promotes an oxidising atmosphere and can lead to the formations of new phases. For $\mathrm{B}_{4} \mathrm{C}$, these oxide films are brittle in nature and tend to reduce the mechanical properties. However, for $\mathrm{Al}_{2} \mathrm{O}_{3}$ and $\mathrm{SiC}$, these oxide films can improve their wettability. Another recommended method of improving the interface wettability consists of the coating with a differing element such as $\mathrm{Cu}$ and $\mathrm{Ni}$, as these are reported to improve the incorporation and inhibit agglomeration. The addition of the particles to the melt is a crucial stage in the MMC processing as particles can trap oxides formed at the melt surface. To prevent these issues, the authors have introduced the particles packed in aluminium foil into the vortex or through injection assisted by an inert gas. Although both methods are effective, packing in aluminium foil can induce an early agglomeration, particularly for nanoparticles [124]. In both a melt additive and ball milling powder approaches, the use of $1-2 \mathrm{wt} . \% \mathrm{Mg}$ contributes to the reduction of interfacial energy $[82,95,177]$. Higher Mg content (>2 wt. $\%$ ) will lead to the formation and coarsening of $\mathrm{Mg}_{2} \mathrm{Si}$ and $\mathrm{Mg}_{5} \mathrm{Al}_{8}$ as well as the increase in porosity [178]. Additionally, its positive effect on melt fluidity can also be considered to improve the filling capacity.

\subsection{Processing Temperature}

Similar to particle preheating, the melting temperature can be intimately related to the contact angle of the reinforcement. Even though higher temperatures can improve wettability, a melt temperature higher than $900{ }^{\circ} \mathrm{C}$ will result in detrimental effects as an aluminium affinity for oxygen is prone to form oxides in the casting. Considering the thermal properties of the ceramic particles, the heat loss from the particle will be significantly lower than the melt, leading to longer solidification times and relatively inferior tensile properties. Considering their individual wettability, a melt temperature of $750{ }^{\circ} \mathrm{C}$ is recommended for $\mathrm{Al}_{2} \mathrm{O}_{3}$ and $\mathrm{SiC}$, along with $850{ }^{\circ} \mathrm{C}$ for $\mathrm{B}_{4} \mathrm{C}$ particle. While using steel die, it is recommended to pre-heat it between $250{ }^{\circ} \mathrm{C}$ and $300^{\circ} \mathrm{C}$, while higher temperatures are not reported as being beneficial to enhance mechanical properties or wettability $[179,180]$.

\subsection{Melt Stirring}

Considering a particle behaviour in the melt, longer stirring periods are often desirable as it increases the chance of a successful interfacial wetting [173]. However, as discussed in previous chapters, stir casting parameters are subject to change as its ability to dispersing particles trajectory, without projecting to the crucible walls or allowing them to settle, is found to be highly dependable on its individual particle density and size. Independently of the size, $B_{4} C$ does not require a high stirring speed as its density $\left(2.52 \mathrm{~g} / \mathrm{cm}^{3}\right)$ is close to that of most aluminium alloys and can endure longer immersion periods without any negative effect. Therefore, a stirring period of $10-15 \mathrm{~min}$ at $300-350 \mathrm{rpm}$ is recommended. Although longer stirring periods would improve the contact angle between the melt and the reinforcement, publication regarding $\mathrm{SiC}$ composite seem to report higher tensile properties when a short timed high-speed stirring methodology is adopted. Considering the several publications, a short stirring period of $5-10 \mathrm{~min}$ is recommended at $650 \mathrm{rpm}$ or higher. Similar to the previous, $\mathrm{Al}_{2} \mathrm{O}_{3}$ does not require an extended stirring period $(10 \mathrm{~min})$ as prolonged immersion times led to an increase in gas accumulation and porosity which verified that a stirring speed of $450 \mathrm{rpm}$ is optimal to achieving a homogenous distribution. Regarding the stirring apparatus characteristics, very few publications were found, usually addressing these issues empirically or through numeric simulation. Conclusions converge to the idea that a 3-4 bladed multi-stage impeller with a blade/crucible diameter of 0.5 is indicated as optimal to mitigate stagnant zones and thus avoid particles settlement. Likewise, a $30^{\circ}-45^{\circ}$ blade angle is recommended as it creates sufficient shearing force and upward fluid motion that ensures the suspension of the reinforcement particles. 


\subsection{Ultrasonic Melt Treatment}

Additionally, ultrasonic melt treatment can be recommended as a complementing method for its grain refining as well as the wetting effect [173], distribution and deagglomeration impact in the MMC processing. When relying fully on UST, it is suggested to introduce particles directly under the acoustic horn, the area of effect in order to maximise its de-agglomeration effects [173]. Despite its benefits, it is advised to complement the technique with mechanical stirring as the achievable dispersion tends to be more homogenous [68]. Although UST is generally a quick procedure $(<1 \mathrm{~min})$, a treatment period between 2 and $3 \mathrm{~min}$ is recommended before the gains per treatment start decreasing [77,124].

Table 3. Recommendations [10,68,71,73,75-77,79,81-83,91,94,95,163].

\begin{tabular}{|c|c|c|c|c|}
\hline Category & Processing Parameter & $\mathrm{Al}_{2} \mathrm{O}_{3}$ & $\mathrm{SiC}$ & $\mathrm{B}_{4} \mathrm{C}$ \\
\hline \multirow{4}{*}{$\begin{array}{c}\text { Pre- } \\
\text { processing }\end{array}$} & Particle temperature & $700^{\circ} \mathrm{C}$ & $700{ }^{\circ} \mathrm{C}$ & $<300^{\circ} \mathrm{C}$ \\
\hline & Introduction & \multirow{2}{*}{\multicolumn{3}{|c|}{$\begin{array}{c}\text { Injection *; Vortex in } \mathrm{Al} \text { foil } \\
1 \mathrm{wt} \% \mathrm{Mg} \text { and/or } \mathrm{Al}\end{array}$}} \\
\hline & Wetting agent & & & \\
\hline & Coating/Oxidation & $\mathrm{Cu}, \mathrm{Ni}$ & $\mathrm{Cu}, \mathrm{Ni}$ & $\mathrm{Ti}$ \\
\hline \multirow{6}{*}{$\begin{array}{c}\text { Main } \\
\text { processing }\end{array}$} & Melt Temperature & \multirow{6}{*}{$\begin{array}{c}750^{\circ} \mathrm{C} \\
-b\end{array}$} & $750^{\circ} \mathrm{C}$ & $850^{\circ} \mathrm{C}$ \\
\hline & Flux & & $-b$ & $\mathrm{~K}_{2} \mathrm{TiF}_{6}$ \\
\hline & Additives & & 1 wt. $\% \mathrm{Mg}^{\mathrm{a}}$ & \\
\hline & Degassing & & UST ${ }^{*}$, Argon, $\mathrm{N}_{2}$ & \\
\hline & Protective gas & & Argon, $\mathrm{N}_{2}$ & \\
\hline & Die Temperature & & $250-300^{\circ} \mathrm{C}$ & \\
\hline \multirow{5}{*}{$\begin{array}{l}\text { Stirring } \\
\text { specific }\end{array}$} & Stirring speed & $450 \mathrm{rpm}$ & $650 \mathrm{rpm}$ & 300-350 rpm \\
\hline & Stirring period & \multirow[t]{4}{*}{$10 \mathrm{~min}$} & $5-10 \mathrm{~min}$ & $10-15 \mathrm{~min}$ \\
\hline & Blade angle & & $30^{\circ} *, 45^{\circ}$ & \\
\hline & Number of blades & & $3-4$ & \\
\hline & Impeller stage & & Multi-stage & \\
\hline \multirow{3}{*}{$\begin{array}{c}\text { UST } \\
\text { specific }\end{array}$} & UST frequency & \multirow{3}{*}{\multicolumn{3}{|c|}{$\begin{array}{c}20 \mathrm{kHz} \\
1.8-2.8 \mathrm{~kW} \\
2-3 \mathrm{~min}\end{array}$}} \\
\hline & UST power & & & \\
\hline & UST time & & & \\
\hline
\end{tabular}

* Preferable or optimal; ${ }^{\mathrm{a}}$ If not present in pre-processing; ${ }^{\mathrm{b}}$ no specific effect on MMC as it improves general casting quality.

\section{Conclusions}

A wide range of methods and techniques were presented and discussed in the context of ceramic particle wettability, distribution and de-agglomeration. As composite properties are dependent on particle type and volume fraction, current systematic focused on $\mathrm{Al}_{2} \mathrm{O}_{3}$, $\mathrm{B}_{4} \mathrm{C}$ and $\mathrm{SiC}$. Likewise, parameter recommendation is formulated for these particles.

Current MMC research tends to be focused on material property enhancement. However, it is suggested that nanoparticles may have a lower reinforcement content threshold as the presence of a large number of nanoparticles tends to promote agglomeration and induce porosity. In contrast, micro-reinforcement has a higher chance of success at higher volume fractions, allowing both particle incorporation and mechanical properties [90,181]. For each particle type and size, some authors have suggested there is an optimum amount for each particle and when this threshold is overlapped the volume of porosity and agglomerated clusters cannot be ignored [55,84,182].

Among the other MMC-manufacturing techniques, stir-casting is restrained in its reinforcement volume fraction, and the course of action for both nano- and micro-particles is to enhance mechanical property/content ratio efficiency. This comprises the mitigation of porosity levels in the final MMC cast samples, and extend the optimum reinforcement to higher volume fractions. As discussed in previous chapters, the fabrication of hybrid composites and the incorporation of multiple sized particles is the most promising step. However, there is no current sufficient literature to show the influence on mechanical properties and its correlation with optimal processing parameters.

Additionally, a crucial parameter that is not sufficiently addressed in the literature is the analysis of the particle-matrix reinforcement ratio (e.g., combining wettability factor [89] 
and the reinforcement incorporation factor [90]), which quantifies the volume fraction of particles that effectively act as reinforcements in the final cast components.

Author Contributions: Conceptualisation, J.G., V.H.C. and H.P.; methodology, J.G.; validation, H.P., V.H.C. and J.C.T.; formal analysis, J.G.; investigation, J.G.; resources, J.C.T.; data curation, J.G.; writing—original draft preparation, J.G., V.H.C. and H.P.; writing—review and editing, J.G., V.H.C., H.P. and J.C.T.; visualisation, J.G.; supervision, H.P., V.H.C. and J.C.T.; project administration, H.P.; funding acquisition, H.P. All authors have read and agreed to the published version of the manuscript.

Funding: This work was supported by PTDC/EMEEME/30967/2017 and NORTE-0145-FEDER030967, co-financed by the European Regional Development Fund (ERDF), through the Operational Programme for Competitiveness and Internationalization (COMPETE 2020), under Portugal 2020, and by the Fundação para a Ciência e a Tecnologia-FCT I.P. national funds. Also, this work was supported by Portuguese FCT, under the reference project UIDB/04436/2020, Stimulus of Scientific Employment Application CEECIND/03991/2017, research doctoral Grant 2020.08564.BD.

Institutional Review Board Statement: Not applicable.

Informed Consent Statement: Not applicable.

Conflicts of Interest: Authors declare no conflict of interest.

\section{References}

1. Binnemans, K.; Jones, P.T.; Müller, T.; Yurramendi, L. Rare Earths and the Balance Problem: How to Deal with Changing Markets? J. Sustain. Metall. 2018, 4, 126-146. [CrossRef]

2. European Commission. Transport 2050: Commission Outlines Ambitious Plan to Increase Mobility and Reduce Emissions. 2011. Available online: https:/ / ec.europa.eu/commission/presscorner/detail/en/IP_11_372 (accessed on 25 November 2020).

3. European Commission. Roadmap to a Single European Transport Area-Towards a Competitive and Resource Efficient Transport System; Publications Office of the European Union: Brussels, Belgium, 2020.

4. Mallick, P.K. Designing lightweight vehicle body. Materials, Design and Manufacturing for Lightweight Vehicles; Elsevier: Amsterdam, The Netherlands, 2021; pp. 405-432; ISBN 9780128187128.

5. De Vos, P. Railway Noise in Europe State of the Art Report; UIC-ETF (Railway Technical Publications): Paris, France, 2016; ISBN 978-2-7461-2473-8.

6. Blengini, G.A.; El Latunussa, C.; Eynard, U.; Torres de Matos, C.; Wittmer, D.M.A.G.; Georgitzikis, K.; Pavel, C.C.; Carrara, S.; Mancini, L.; Unguru, M.; et al. Study on the EU's List of Critical Raw Materials (2020): Final Report; Publications Office of the European Union: Luxembourg, 2020; ISBN 9789276210498.

7. Zhu, Y.; Chappuis, L.B.; de Kleine, R.; Kim, H.C.; Wallington, T.J.; Luckey, G.; Cooper, D.R. The coming wave of aluminum sheet scrap from vehicle recycling in the United States. Resour. Conserv. Recycl. 2021, 164, 105208. [CrossRef]

8. Soo, V.K.; Doolan, M.; Compston, P.; Duflou, J.R.; Peeters, J.; Umeda, Y. The influence of end-of-life regulation on vehicle material circularity: A comparison of Europe, Japan, Australia and the US. Resour. Conserv. Recycl. 2020, 105294. [CrossRef]

9. Modi, S.; Vadhavkar, A. Technology Roadmap: Materials and Manufacturing. Available online: https://www.cargroup.org/ publication/technology-roadmap-materials-and-manufacturing/ (accessed on 23 March 2020).

10. Krishnan, P.K.; Christy, J.V.; Arunachalam, R.; Mourad, A.-H.I.; Muraliraja, R.; Al-Maharbi, M.; Murali, V.; Chandra, M.M. Production of aluminum alloy-based metal matrix composites using scrap aluminum alloy and waste materials: Influence on microstructure and mechanical properties. J. Alloy. Compd. 2019, 784, 1047-1061. [CrossRef]

11. Yu, L.; Yan, H.; Chen, J.; Xia, W.; Su, B.; Song, M. Effects of solid solution elements on damping capacities of binary magnesium alloys. Mater. Sci. Eng. A 2020, 772, 138707. [CrossRef]

12. Zhou, X.; Yan, H.; Chen, J.; Xia, W.; Su, B.; Yu, L.; Huang, W.; Song, M. Effects of low temperature aging precipitates on damping and mechanical properties of ZK60 magnesium alloy. J. Alloy. Compd. 2020, 819, 152961. [CrossRef]

13. Hu, X.-S.; Wang, X.-J.; He, X.-D.; Wu, K.; Zheng, M.-Y. Low frequency damping capacities of commercial pure magnesium. Trans. Nonferrous Met. Soc. China 2012, 22, 1907-1911. [CrossRef]

14. Puga, H.; Carneiro, V.; Barbosa, J.; Vieira, V. Effect of Ultrasonic Treatment in the Static and Dynamic Mechanical Behavior of AZ91D Mg Alloy. Metals 2015, 5, 2210-2221. [CrossRef]

15. Chuah, C.Y.; Lee, Y.; Bae, T.-H. Potential of adsorbents and membranes for SF6 capture and recovery: A review. Chem. Eng. J. 2021, 404, 126577. [CrossRef]

16. Cashion, S.P.; Ricketts, N.J.; Hayes, P.C. Characterisation of protective surface films formed on molten magnesium protected by air/SF6 atmospheres. J. Light Met. 2002, 2, 37-42. [CrossRef]

17. Lopes, V.; Puga, H.; Barbosa, J.; Teixeira, J.C. Effect of Yttria Mould Coating on the Investment Casting of AZ91D-1 wt.\% CaO Magnesium Alloy. Inter Met. 2020, 14, 98-107. [CrossRef]

18. Jafari, H.; Idris, M.H.; Ourdjini, A.; Abdul Kadir, M.R. An investigation on interfacial reaction between in-situ melted AZ91D magnesium alloy and ceramic shell mold during investment casting process. Mater. Chem. Phys. 2013, 138, 672-681. [CrossRef] 
19. Carneiro, V.H.; Puga, H. T6 Heat Treatment Impact on the Random Frequency Vibration Stress of Al-Si-Mg Alloys. Met. Mater. Int. 2019, 25, 880-887. [CrossRef]

20. Carneiro, V.H.; Puga, H.; Meireles, J. Heat treatment as a route to tailor the yield-damping properties in A356 alloys. Mater. Sci. Eng. A 2018, 729, 1-8. [CrossRef]

21. Carneiro, V.H.; Puga, H. Solution Treatment Enhances Both Static and Damping Properties of Al-Si-Mg alloys. Metall. Mater. Trans. A 2018, 49, 5942-5945. [CrossRef]

22. Sjölander, E.; Seifeddine, S. The heat treatment of Al-Si-Cu-Mg casting alloys. J. Mater. Process. Technol. 2010, $210,1249-1259$. [CrossRef]

23. Totten, G.E.; MacKenzie, D.S. Handbook of Aluminum; M. Dekker: New York, NY, USA; Basel, Switzerland, 2003; ISBN 9780824704940.

24. Georgantzia, E.; Gkantou, M.; Kamaris, G.S. Aluminium alloys as structural material: A review of research. Eng. Struct. 2021, 227, 111372. [CrossRef]

25. Ervina Efzan, M.N.; Kong, H.J.; Kok, C.K. Review: Effect of Alloying Element on Al-Si Alloys. AMR 2013, 845, 355-359. [CrossRef]

26. Ding, W.; Zhao, X.; Chen, T.; Zhang, H.; Liu, X.; Cheng, Y.; Lei, D. Effect of rare earth Y and Al-Ti-B master alloy on the microstructure and mechanical properties of 6063 aluminum alloy. J. Alloy. Compd. 2020, 830, 154685. [CrossRef]

27. Gursoy, O.; Timelli, G. Lanthanides: A focused review of eutectic modification in hypoeutectic Al-Si alloys. J. Mater. Res. Technol. 2020, 9, 8652-8666. [CrossRef]

28. Puga, H.; Barbosa, J.; Carneiro, V.H. The Role of Acoustic Pressure during Solidification of AlSi7Mg Alloy in Sand Mold Casting. Metals 2019, 9, 490. [CrossRef]

29. Puga, H.; Carneiro, V.H.; Barbosa, J.; Soares, D. Effect of grain and secondary phase morphologies in the mechanical and damping behavior of Al7075 alloys. Met. Mater. Int. 2016, 22, 863-871. [CrossRef]

30. Puga, H.; Carneiro, V.H. Light-Alloy Melt Ultrasonication: Shorter T6 with Higher Precipitation Strengthening. Met. Mater. Int. 2020, 698, 577. [CrossRef]

31. Ghosh, M.; Miroux, A.; Kestens, L.A.I. Experimental study and modelling of the role of solutes, precipitates and temperature on the work-hardening of AA6xxx aluminium alloys. Mater. Sci. Eng. A 2020, 140615. [CrossRef]

32. Santos, M.C.; Machado, A.R.; Sales, W.F.; Barrozo, M.A.S.; Ezugwu, E.O. Machining of aluminum alloys: A review. Int. J. Adv. Manuf. Technol. 2016, 86, 3067-3080. [CrossRef]

33. Puga, H.; Grilo, J.; Carneiro, V.H. Ultrasonic Assisted Turning of Al alloys: Influence of Material Processing to Improve Surface Roughness. Surfaces 2019, 2, 24. [CrossRef]

34. Puga, H.; Grilo, J.; Oliveira, F.J.; Silva, R.F.; Girão, A.V. Influence of external loading on the resonant frequency shift of ultrasonic assisted turning: Numerical and experimental analysis. Int. J. Adv. Manuf. Technol. 2019, 101, 2487-2496. [CrossRef]

35. Olakanmi, E.O.; Cochrane, R.F.; Dalgarno, K.W. A review on selective laser sintering/melting (SLS/SLM) of aluminium alloy powders: Processing, microstructure, and properties. Prog. Mater. Sci. 2015, 74, 401-477. [CrossRef]

36. Aboulkhair, N.T.; Simonelli, M.; Parry, L.; Ashcroft, I.; Tuck, C.; Hague, R. 3D printing of Aluminium alloys: Additive Manufacturing of Aluminium alloys using selective laser melting. Prog. Mater. Sci. 2019, 106, 100578. [CrossRef]

37. Cao, C.; Yao, G.; Jiang, L.; Sokoluk, M.; Wang, X.; Ciston, J.; Javadi, A.; Guan, Z.; de Rosa, I.; Xie, W.; et al. Bulk ultrafine grained/nanocrystalline metals via slow cooling. Sci. Adv. 2019, 5, eaaw2398. [CrossRef]

38. Robles Hernandez, F.C.; Herrera Ramírez, J.M.; Mackay, R. Al-Si Alloys: Automotive, Aeronautical, and Aerospace Applications, 1st ed.; Springer International Publishing: Cham, Switzerland, 2017; ISBN 978-3-319-58380-8.

39. STARKE, E.A. Heat-Treatable Aluminum Alloys. Aluminum Alloys-Contemporary Research and Applications; Elsevier: Amsterdam, The Netherlands, 1989; pp. 35-63; ISBN 9780123418319.

40. Tiryakiō̄lu, M.; Campbell, J. Quality Index for Aluminum Alloy Castings. Int. J. Met. 2014, 8, 39-42. [CrossRef]

41. Carneiro, V.H.; Puga, H.; Meireles, J. Positive, zero and negative Poisson's ratio non-stochastic metallic cellular solids: Dependence between static and dynamic mechanical properties. Compos. Struct. 2019, 226, 111239. [CrossRef]

42. Clyne, T.W.; Withers, P.J. An Introduction to Metal Matrix Composites; Cambridge University Press: Cambridge, UK, 1993; ISBN 0521483573.

43. Basak, A.K.; Pramanik, A.; Prakash, C. Deformation and strengthening of SiC reinforced Al-MMCs during in-situ micro-pillar compression. Mater. Sci. Eng. A 2019, 763, 138141. [CrossRef]

44. Zhang, Z.; Chen, D.L. Contribution of Orowan strengthening effect in particulate-reinforced metal matrix nanocomposites. Mater. Sci. Eng. A 2008, 483-484, 148-152. [CrossRef]

45. Samal, P.; Vundavilli, P.R.; Meher, A.; Mahapatra, M.M. Recent progress in aluminum metal matrix composites: A review on processing, mechanical and wear properties. J. Manuf. Process. 2020, 59, 131-152. [CrossRef]

46. Madeira, S.; Carvalho, O.; Carneiro, V.H.; Soares, D.; Silva, F.S.; Miranda, G. Damping capacity and dynamic modulus of hot pressed AlSi composites reinforced with different SiC particle sized. Compos. Part B Eng. 2016, 90, 399-405. [CrossRef]

47. Madeira, S.; Miranda, G.; Carneiro, V.H.; Soares, D.; Silva, F.S.; Carvalho, O. The effect of SiCp size on high temperature damping capacity and dynamic Young's modulus of hot-pressed AlSi-SiCp MMCs. Mater. Des. 2016, 93, 409-417. [CrossRef]

48. Nturanabo, F.; Masu, L.; Baptist Kirabira, J. Novel Applications of Aluminium Metal Matrix Composites; IntechOpen: London, UK, 2020. Available online: http:/ / dx.doi.org/10.5772/intechopen.86225 (accessed on 20 June 2020). 
49. Ramanathan, A.; Krishnan, P.K.; Muraliraja, R. A review on the production of metal matrix composites through stir castingFurnace design, properties, challenges, and research opportunities. J. Manuf. Process. 2019, 42, 213-245. [CrossRef]

50. Amirkhanlou, S.; Niroumand, B. Effects of reinforcement distribution on low and high temperature tensile properties of $\mathrm{Al} 356 / \mathrm{SiCp}$ cast composites produced by a novel reinforcement dispersion technique. Mater. Sci. Eng. A 2011, 528, 7186-7195. [CrossRef]

51. Alaneme, K.K.; Fajemisin, A.V. Evaluation of the damping behaviour of Al-Mg-Si alloy based composites reinforced with steel, steel and graphite, and silicon carbide particulates. Eng. Sci. Technol. Int. J. 2018, 21, 798-805. [CrossRef]

52. Suresh, S.; Sudhakara, D.; Vinod, B. Investigation on Tribological and Machining Characteristics of Al 7075/MWCNTs Nanocomposites. J. Bio Tribo Corros. 2020, 6, 627. [CrossRef]

53. Klasik, A.; Sobczak, J.; Pietrzak, K. Changes in properties of aluminium matrix composite reinforced with SiC particles after multiple remelting. Mater. Res. Innov. 2011, 15, s249-s252. [CrossRef]

54. Shalaby, E.A.M.; Churyumov, A.Y.; Besisa, D.H.A.; Daoud, A.; Abou El-khair, M.T. A Comparative Study of Thermal Conductivity and Tribological Behavior of Squeeze Cast A359/AlN and A359/SiC Composites. J. Mater. Eng. Perform. 2017, 26, 3079-3089. [CrossRef]

55. Mazahery, A.; Shabani, M.O. Characterization of cast A356 alloy reinforced with nano SiC composites. Trans. Nonferrous Met. Soc. China 2012, 22, 275-280. [CrossRef]

56. Ahmad, S.N.; Hashim, J.; Ghazali, M.I. The Effects of Porosity on Mechanical Properties of Cast Discontinuous Reinforced Metal-Matrix Composite. J. Compos. Mater. 2005, 39, 451-466. [CrossRef]

57. Hu, K.; Du, Y.; Lü, S.-1.; Wu, S.-s. Effects of nano-SiCp content on microstructure and mechanical properties of SiCp/A356 composites assisted with ultrasonic treatment. Trans. Nonferrous Met. Soc. China 2018, 28, 2173-2180. [CrossRef]

58. Hashim, J.; Looney, L.; Hashmi, M.S.J. Particle distribution in cast metal matrix composites-Part I. J. Mater. Process. Technol. 2002, 123, 251-257. [CrossRef]

59. Hashim, J.; Looney, L.; Hashmi, M.S.J. Particle distribution in cast metal matrix composites—Part II. J. Mater. Process. Technol. 2002, 123, 258-263. [CrossRef]

60. Eustathopoulos, N. Wetting by Liquid Metals-Application in Materials Processing: The Contribution of the Grenoble Group. Metals 2015, 5, 350-370. [CrossRef]

61. Kumar, M.; Gupta, R.K.; Pandey, A. A Review on Fabrication and Characteristics of Metal Matrix Composites Fabricated By Stir Casting. IOP Conf. Ser.: Mater. Sci. Eng. 2018, 377, 12125. [CrossRef]

62. Grilo, J.; Puga, H.; Carneiro, V.H.; Tohidi, S.D.; Barbosa, F.V.; Teixeira, J.C. Effect of Hybrid Ultrasonic and Mechanical Stirring on the Distribution of $\mathrm{m}-\mathrm{SiCp}$ in A356 Alloy. Metals 2020, 10, 610. [CrossRef]

63. Moher, D.; Liberati, A.; Tetzlaff, J.; Altman, D.G. The PRISMA Group. Preferred Reporting Items for Systematic Reviews and Meta-Analyses: The PRISMA Statement. PLoS Med. 2009, 6, e1000097. [CrossRef]

64. Kumar, A.; Lal, S.; Kumar, S. Fabrication and characterization of $\mathrm{A} 359 / \mathrm{Al}_{2} \mathrm{O}_{3}$ metal matrix composite using electromagnetic stir casting method. J. Mater. Res. Technol. 2013, 2, 250-254. [CrossRef]

65. Tahamtan, S.; Halvaee, A.; Emamy, M.; Zabihi, M.S. Fabrication of $\mathrm{Al} / \mathrm{A} 206-\mathrm{Al}_{2} \mathrm{O}_{3}$ nano/micro composite by combining ball milling and stir casting technology. Mater. Des. 2013, 49, 347-359. [CrossRef]

66. Hosseini, N.; Karimzadeh, F.; Abbasi, M.H.; Enayati, M.H. Tribological properties of $\mathrm{Al}_{6061}-\mathrm{Al}_{2} \mathrm{O}_{3}$ nanocomposite prepared by milling and hot pressing. Mater. Des. 2010, 31, 4777-4785. [CrossRef]

67. Goyal, H.; Mandal, N.; Roy, H.; Mitra, S.K.; Mondal, B. Multi Response Optimization for Processing Al-SiCp Composites: An Approach Towards Enhancement of Mechanical Properties. Trans. Indian Inst. Met. 2015, 68, 453-463. [CrossRef]

68. Aybarç, U.; Ertuğrul, O.; Seydibeyoğlu, M.Ö. Effect of $\mathrm{Al}_{2} \mathrm{O}_{3}$ Particle Size on Mechanical Properties of Ultrasonic-Assisted Stir-Casted Al A356 Matrix Composites. Int. J. Met. 2020, 377, 1-12. [CrossRef]

69. Adeosun, S.O.; Akpan, E.I.; Gbenebor, O.P.; Balogun, S.A. Ductility and hardness of chloride cleaned AA6011/SiCp composites Trans. Nonferrous Met. Soc. China 2016, 26, 339-347. [CrossRef]

70. Mahesh, V.P.; Nair, P.S.; Rajan, T.P.D.; Pai, B.C.; Hubli, R.C. Processing of surface-treated boron carbide-reinforced aluminum matrix composites by liquid-metal stir-casting technique. J. Compos. Mater. 2011, 45, 2371-2378. [CrossRef]

71. Raj, R.; Thakur, D.G. Influence of boron carbide content on the microstructure, tensile strength and fracture behavior of boron carbide reinforced aluminum metal matrix composites. Mater. Werkst. 2018, 49, 1068-1080. [CrossRef]

72. Pourhosseini, S.; Beygi, H.; Sajjadi, S.A. Effect of metal coating of reinforcements on the microstructure and mechanical properties of $\mathrm{Al}-\mathrm{Al}_{2} \mathrm{O}_{3}$ nanocomposites. Mater. Sci. Technol. 2018, 34, 145-152. [CrossRef]

73. Yang, D.; Qiu, F.; Zhao, W.; Shen, P.; Wang, H.; Jiang, Q. Effects of Ti-coating layer on the distribution of SiCP in the SiCP/2014Al composites. Mater. Des. 2015, 87, 1100-1106. [CrossRef]

74. Zhang, L.-J.; Yang, D.-L.; Qiu, F.; Wang, J.-G.; Jiang, Q.-C. Effects of reinforcement surface modification on the microstructures and tensile properties of SiCp/Al2014 composites. Mater. Sci. Eng. A 2015, 624, 102-109. [CrossRef]

75. Abdizadeh, H.; Baghchesara, M.A. Optimized Parameters for Enhanced Properties in Al-B4C Composite. Arab. J. Sci. Eng. 2018, 43, 4475-4485. [CrossRef]

76. Khademian, M.; Alizadeh, A.; Abdollahi, A. Fabrication and Characterization of Hot Rolled and Hot Extruded Boron Carbide (B4C) Reinforced A356 Aluminum Alloy Matrix Composites Produced by Stir Casting Method. Trans. Indian Inst. Met. 2017, 70, 1635-1646. [CrossRef] 
77. Du, Y.; Yang, X.; Wu, S.; Lü, S.; Hu, K. Development of high strength and toughness nano-SiCp/A356 composites with ultrasonic vibration and squeeze casting. J. Mater. Process. Technol. 2019, 269, 1-9. [CrossRef]

78. Shirvanimoghaddam, K.; Khayyam, H.; Abdizadeh, H.; Karbalaei Akbari, M.; Pakseresht, A.H.; Ghasali, E.; Naebe, M. Boron carbide reinforced aluminium matrix composite: Physical, mechanical characterization and mathematical modelling. Mater. Sci. Eng. A 2016, 658, 135-149. [CrossRef]

79. Yang, X.; Barekar, N.S.; Ji, S.; Dhindaw, B.K.; Fan, Z. Influence of reinforcing particle distribution on the casting characteristics of Al-SiCp composites. J. Mater. Process. Technol. 2020, 279, 116580. [CrossRef]

80. Mehta, V.R.; Sutaria, M.P. Investigation on the Effect of Stirring Process Parameters on the Dispersion of SiC Particles Inside Melting Crucible. Met. Mater. Int. 2020, 17. [CrossRef]

81. Jiang, D.; Yu, J. Fabrication of $\mathrm{Al}_{2} \mathrm{O}_{3} / \mathrm{SiC} / \mathrm{Al}$ Hybrid Nanocomposites Through Solidification Process for Improved Mechanical Properties. Metals 2018, 8, 572. [CrossRef]

82. Amirkhanlou, S.; Niroumand, B. Development of Al356/SiCp cast composites by injection of SiCp containing composite powders. Mater. Des. 2011, 32, 1895-1902. [CrossRef]

83. Jia, S.; Zhang, D.; Xuan, Y.; Nastac, L. An experimental and modeling investigation of aluminum-based alloys and nanocomposites processed by ultrasonic cavitation processing. Appl. Acoust. 2016, 103, 226-231. [CrossRef]

84. Singh, V.K.; Chauhan, S.; Gope, P.C.; Chaudhary, A.K. Enhancement of Wettability of Aluminum Based Silicon Carbide Reinforced Particulate Metal Matrix Composite. High Temp. Mater. Process. 2014. [CrossRef]

85. Amirkhanlou, S.; Niroumand, B. Fabrication and characterization of Al356/SiCp semisolid composites by injecting SiCp containing composite powders. J. Mater. Process. Technol. 2012, 212, 841-847. [CrossRef]

86. Hashim, J.; Looney, L.; Hashmi, M.S.J. The enhancement of wettability of SiC particles in cast aluminium matrix composites. J. Mater. Process. Technol. 2001, 119, 329-335. [CrossRef]

87. Mohammadpour, M.; Azari Khosroshahi, R.; Taherzadeh Mousavian, R.; Brabazon, D. Effect of interfacial-active elements addition on the incorporation of micron-sized SiC particles in molten pure aluminum. Ceram. Int. 2014, 40, 8323-8332. [CrossRef]

88. Panthglin, C.; Boontein, S.; Kajornchaiyakul, J.; Limmaneevichitr, C. The Effects of Zr Addition on the Microstructure and Mechanical Properties of A356-SiC Composites. Inter Met. 2020, 40. [CrossRef]

89. Beygi, H.; Sajjadi, S.A.; Zebarjad, S.M. Microstructural analysis and mechanical characterization of aluminum matrix nanocomposites reinforced with uncoated and Cu-coated alumina particles. Mater. Sci. Eng. A 2014, 607, 81-88. [CrossRef]

90. Akbari, M.K.; Shirvanimoghaddam, K.; Hai, Z.; Zhuiykov, S.; Khayyam, H. Al-TiB 2 micro/nanocomposites: Particle capture investigations, strengthening mechanisms and mathematical modelling of mechanical properties. Mater. Sci. Eng. A 2017, 682, 98-106. [CrossRef]

91. Samiee, A.; Bina, M.H.; Meratian, M. Influence of Surface Modification of Alumina on Improvement of Wetability in Aluminium Matrix Composite. Adv. Mater. Sci. Eng. 2014, 2014, 1-6. [CrossRef]

92. Inegbenebor, A.O.; Bolu, C.A.; Babalola, P.O.; Inegbenebor, A.I.; Fayomi, O.S.I. Aluminum Silicon Carbide Particulate Metal Matrix Composite Development Via Stir Casting Processing. Silicon 2018, 10, 343-347. [CrossRef]

93. Karbalaei Akbari, M.; Baharvandi, H.R.; Mirzaee, O. Fabrication of nano-sized $\mathrm{Al}_{2} \mathrm{O}_{3}$ reinforced casting aluminum composite focusing on preparation process of reinforcement powders and evaluation of its properties. Compos. Part B Eng. 2013, 55, 426-432. [CrossRef]

94. Zheng, J.; Li, Q.; Liu, W.; Shu, G. Microstructure evolution of 15 wt.\% boron carbide/aluminum composites during liquid-stirring process. J. Compos. Mater. 2016, 50, 3843-3852. [CrossRef]

95. Saeed Pashmforoosh; Sadegh Shahriyari; Omid Mirzaee. Evaluation of Mechanical and Microstructure Properties of Mg-Modified Aluminum Matrix Composite by Vortical Casting Method. Met. Mater. Int. 2020, 1-13. [CrossRef]

96. Naidich, J.V. The Wettability of Solids by Liquid Metals; Elsevier: Amsterdam, The Netherlands, 1981; pp. 353-484; ISBN 9780125718141.

97. Taherzadeh Mousavian, R.; Behnamfard, S.; Heidarzadeh, A.; Taherkhani, K.; Azari Khosroshahi, R.; Brabazon, D. Incorporation of SiC Ceramic Nanoparticles into the Aluminum Matrix by a Novel Method: Production of a Metal Matrix Composite. Met. Mater. Int. 2020. [CrossRef]

98. Wu, J.; Zhang, H.; Zhang, Y.; Li, J.; Wang, X. Effect of copper content on the thermal conductivity and thermal expansion of $\mathrm{Al}-\mathrm{Cu}$ /diamond composites. Mater. Des. 2012, 39, 87-92. [CrossRef]

99. Oh, S.-I.; Lim, J.-Y.; Kim, Y.-C.; Yoon, J.; Kim, G.-H.; Lee, J.; Sung, Y.-M.; Han, J.-H. Fabrication of carbon nanofiber reinforced aluminum alloy nanocomposites by a liquid process. J. Alloy. Compd. 2012, 542, 111-117. [CrossRef]

100. Hajjari, E.; Divandari, M.; Mirhabibi, A.R. The effect of applied pressure on fracture surface and tensile properties of nickel coated continuous carbon fiber reinforced aluminum composites fabricated by squeeze casting. Mater. Des. 2010, 31, 2381-2386. [CrossRef]

101. Mousavian, R.T.; Khosroshahi, R.A.; Yazdani, S.; Brabazon, D. Manufacturing of cast A356 matrix composite reinforced with nano- to micrometer-sized SiC particles. Rare Met. 2017, 36, 46-54. [CrossRef]

102. Mousavian, R.T.; Damadi, S.R.; Khosroshahi, R.A.; Brabazon, D.; Mohammadpour, M. A comparison study of applying metallic coating on SiC particles for manufacturing of cast aluminum matrix composites. Int. J. Adv. Manuf. Technol. 2015, 81, 433-444. [CrossRef] 
103. Campbell, J. Complete Casting Handbook: Metal Casting Processes, Metallurgy, Techniques and Design; Butterworth-Heinemann: Oxford, UK; Waltham, MA, USA, 2015; ISBN 9780444635099.

104. Azadi, M.; Zolfaghari, M.; Rezanezhad, S.; Azadi, M. Effects of SiO2 nano-particles on tribological and mechanical properties of aluminum matrix composites by different dispersion methods. Appl. Phys. A 2018, 124, 112. [CrossRef]

105. Ghandvar, H.; Farahany, S.; Idris, J. Wettability Enhancement of SiCp in Cast A356/SiCp Composite Using Semisolid Process. Mater. Manuf. Process. 2015, 30, 1442-1449. [CrossRef]

106. Adeosun, S.O.; Akpan, E.I.; Gbenebor, O.P.; Balogun, S.A. Microstructural Evolution of Chloride-Cleaned Silicon Carbide Aluminum Composites. JOM 2016, 68, 692-700. [CrossRef]

107. Rajan, T.P.D.; Pillai, R.M.; Pai, B.C. Reinforcement coatings and interfaces in aluminium metal matrix composites. J. Mater. Sci. 1998, 33, 3491-3503. [CrossRef]

108. Cong, X.-S.; Shen, P.; Wang, Y.; Jiang, Q. Wetting of polycrystalline SiC by molten Al and Al-Si alloys. Appl. Surf. Sci. 2014, 317, 140-146. [CrossRef]

109. Laurent, V.; Rado, C.; Eustathopoulos, N. Wetting kinetics and bonding of Al and Al alloys on $\alpha$-SiC. Mater. Sci. Eng. A 1996, 205, 1-8. [CrossRef]

110. Mouradoff, L.; Tristant, P.; Desmaison, J.; Labbe, J.C.; Desmaison-Brut, M.; Rezakhanlou, R. Interaction between Liquid Aluminium and Non-Oxide Ceramics (AlN, $\mathrm{Si}_{3} \mathrm{~N}_{4}, \mathrm{SiC}$ ). KEM 1995, 113, 177-188. [CrossRef]

111. Naidich, Y.V.; Chubashov, Y.N.; Ishchuk, N.F.; Krasovskii, V.P. Wetting of some nonmetallic materials by aluminum. Powder Met. Met Ceram 1983, 22, 481-483. [CrossRef]

112. Ksiazek, M.; Sobczak, N.; Mikulowski, B.; Radziwill, W.; Surowiak, I. Wetting and bonding strength in $\mathrm{Al} / \mathrm{Al}_{2} \mathrm{O}_{3}$ system. Mater. Sci. Eng. A 2002, 324, 162-167. [CrossRef]

113. Kannan, C.; Ramanujam, R. Advanced liquid state processing techniques for ex-situ discontinuous particle reinforced nanocomposites: A review. Sci. Technol. Mater. 2018, 30, 109-119. [CrossRef]

114. Pyzik, A.J.; Aksay, I.A.; Sarikaya, M. Microdesigning of Ceramic-Metal Composites. In Ceramic Microstructures'86; Pask, J.A., Evans, A.G., Eds.; Springer: Boston, MA, USA, 1987; pp. 45-54. ISBN 978-1-4612-9074-2.

115. Bao, S.; Tang, K.; Kvithyld, A.; Tangstad, M.; Engh, T.A. Wettability of Aluminum on Alumina. Met. Mater. Trans B 2011, 42, 1358-1366. [CrossRef]

116. Akbari, M.K.; Baharvandi, H.R.; Mirzaee, O. Investigation of particle size and reinforcement content on mechanical properties and fracture behavior of $\mathrm{A} 356-\mathrm{Al}_{2} \mathrm{O}_{3}$ composite fabricated by vortex method. J. Compos. Mater. 2014, 48, 3315-3330. [CrossRef]

117. Gurusamy, P.; Prabu, S.B.; Paskaramoorthy, R. Influence of Processing Temperatures on Mechanical Properties and Microstructure of Squeeze Cast Aluminum Alloy Composites. Mater. Manuf. Process. 2015, 30, 367-373. [CrossRef]

118. Abdizadeh, H.; Ebrahimifard, R.; Baghchesara, M.A. Investigation of microstructure and mechanical properties of nano $\mathrm{MgO}$ reinforced $\mathrm{Al}$ composites manufactured by stir casting and powder metallurgy methods: A comparative study. Compos. Part B: Eng. 2014, 56, 217-221. [CrossRef]

119. Mazahery, A.; Ostadshabani, M. Investigation on mechanical properties of nano- $\mathrm{Al}_{2} \mathrm{O}_{3}$-reinforced aluminum matrix composites. J. Compos. Mater. 2011, 45, 2579-2586. [CrossRef]

120. Shabani, M.O.; Baghani, A.; Khorram, A.; Heydari, F. Evaluation of Fracture Mechanisms in Al-Si Metal Matrix Nanocomposites Produced by Three Methods of Gravity Sand Casting, Squeeze Casting and Compo Casting in Semi-Solid State. Silicon 2020, 12, 2977-2987. [CrossRef]

121. Evans, A.; San Marchi, C.; Mortensen, A. Metal Matrix Composites in Industry: An Introduction and a Survey/by Alexander Evans, Christopher San Marchi, Andreas Mortensen; Kluwer Academic: Dordrecht, The Netherlands; London, UK, 2003; ISBN 978-1-4020-7521-6.

122. Su, H.; Gao, W.L.; Zhang, H.; Liu, H.B.; Lu, J.; Lu, Z. Study on preparation of large sized nanoparticle reinforced aluminium matrix composite by solid-liquid mixed casting process. Mater. Sci. Technol. 2012, 28, 178-183. [CrossRef]

123. Taherzadeh Mousavian, R.; Azari Khosroshahi, R.; Yazdani, S.; Brabazon, D.; Boostani, A.F. Fabrication of aluminum matrix composites reinforced with nano- to micrometer-sized SiC particles. Mater. Des. 2016, 89, 58-70. [CrossRef]

124. Du, Y.; Hu, K.; Lü, S.; Wu, S.; Gao, Q. Preparation and properties of nano-SiC p/A356 composites synthesised with a new process. Mater. Sci. Technol. 2018, 34, 1415-1424. [CrossRef]

125. Amirkhanlou, S.; Niroumand, B. Synthesis and characterization of 356-SiCp composites by stir casting and compocasting methods. Trans. Nonferrous Met. Soc. China 2010, 20, s788-s793. [CrossRef]

126. Manning, C.R.; Gurganus, T.B. Wetting of Binary Aluminum Alloys in Contact with Be, B4C, and Graphite. J. Am. Ceram. Soc. 1969, 52, 115-118. [CrossRef]

127. Shahriyari, S.; Pashmforoosh, S.; Mirzaee, O. Investigation of the Effect of Sr on the Mechanical Properties and Microstructure of Nano-Alumina Reinforced Aluminum Matrix Composites by the Vortical Casting Method. Met. Mater. Int. 2020, 54, 121. [CrossRef]

128. Hanizam, H.; Salleh, M.S.; Omar, M.Z.; Sulong, A.B. Effects of mechanical stirring and short heat treatment on thixoformed of carbon nanotube aluminium alloy composite. J. Alloy. Compd. 2019, 788, 83-90. [CrossRef]

129. Hu, Q.; Zhao, H.; Li, F. Effects of Manufacturing Processes on Microstructure and Properties of Al/A356-B 4 C Composites. Mater. Manuf. Process. 2016, 31, 1292-1300. [CrossRef]

130. Mazahery, A.; Ostad Shabani, M. Mechanical Properties of Squeeze-Cast A356 Composites Reinforced with B4C Particulates. J. Mater. Eng. Perform. 2012, 21, 247-252. [CrossRef] 
131. Zhang, W.Y.; Du, Y.H.; Zhang, P. Vortex-free stir casting of Al-1.5 wt.\% Si-SiC composite. J. Alloy. Compd. 2019, 787, 206-215. [CrossRef]

132. Mohammadjafar Hadad; Abolfazl Babazade; Majid Safarabadi. Investigation and comparison of the effect of graphene nanoplates and carbon nanotubes on the improvement of mechanical properties in the stir casting process of aluminum matrix nanocomposites. Int. J. Adv. Manuf. Technol. 2020, 109, 2535-2547. [CrossRef]

133. Samal, B.P.; Misra, A.K.; Panigrahi, S.C.; Mishra, S.C. Plunger technique: A new approach to stir casting AMMC preparation. J. Mater. Metall. Eng. 2013, 3, 2231-3818.

134. Prakash, S.; Sasikumar, R.; Natarajan, E.; Suresha, B. Influence of Feeding Techniques in Bottom Tapping Stir Casting Process for Fabrication of Alumina Nano-filler-reinforced Aluminium Composites. Trans. Indian Inst. Met. 2020, 73, 1265-1272. [CrossRef]

135. Suresh, N.; Venkateswaran, S.; Seetharamu, S. Studies on eutectic Al-Si alloy-flyash composites. Int. J. Cast Met. Res. 2011, 24, 118-123. [CrossRef]

136. Kalaiselvan, K.; Murugan, N.; Parameswaran, S. Production and characterization of AA6061-B4C stir cast composite. Mater. Des. 2011, 32, 4004-4009. [CrossRef]

137. Toptan, F.; Kilicarslan, A.; Karaaslan, A.; Cigdem, M.; Kerti, I. Processing and microstructural characterisation of AA 1070 and AA 6063 matrix B4Cp reinforced composites. Mater. Des. 2010, 31, S87-S91. [CrossRef]

138. Sahu, M.K.; Sahu, R.K. Optimization of Stirring Parameters Using CFD Simulations for HAMCs Synthesis by Stir Casting Process. Trans. Indian Inst. Met. 2017, 70, 2563-2570. [CrossRef]

139. Meti, V.K.V.; Shirur, S.; Nampoothiri, J.; Ravi, K.R.; Siddhalingeshwar, I.G. Synthesis, Characterization and Mechanical Properties of AA7075 Based MMCs Reinforced with $\mathrm{TiB}_{2}$ Particles Processed Through Ultrasound Assisted In-Situ Casting Technique. Trans. Indian Inst. Met. 2018, 71, 841-848. [CrossRef]

140. Abdizadeh, H.; Vajargah, P.H.; Baghchesara, M.A. Fabrication of MgO nanoparticulates reinforced aluminum matrix composites using stir-casting method. Kovove Mater. 2016, 52, 319-326. [CrossRef]

141. Chak, V.; Chattopadhyay, H. Fabrication and heat treatment of graphene nanoplatelets reinforced aluminium nanocomposites. Mater. Sci. Eng. A 2020, 791, 139657. [CrossRef]

142. Chen, F.; Zhao, H.; Zhu, G.; Fu, P.; Xia, L. Experimental and numerical analysis of flow behavior and particle distribution in A356/SiCp composite casting. Exp. Therm. Fluid Sci. 2015, 68, 39-47. [CrossRef]

143. Elshalakany, A.B.; Osman, T.A.; Khattab, A.; Azzam, B.; Zaki, M. Microstructure and Mechanical Properties of MWCNTs Reinforced A356 Aluminum Alloys Cast Nanocomposites Fabricated by Using a Combination of Rheocasting and Squeeze Casting Techniques. J. Nanomater. 2014, 2014, 1-14. [CrossRef]

144. Adebisi, A.A.; Maleque, M.A.; Ali, M.Y.; Bello, K.A. Effect of variable particle size reinforcement on mechanical and wear properties of 6061Al-SiC p composite. Compos. Interfaces 2016, 23, 533-547. [CrossRef]

145. Lakshmikanthan, A.; Udayagiri, S.B.; Koppad, P.G.; Gupta, M.; Munishamaiah, K.; Bontha, S. The effect of heat treatment on the mechanical and tribological properties of dual size SiC reinforced A357 matrix composites. J. Mater. Res. Technol. 2020, 9 , 6434-6452. [CrossRef]

146. Gayathri, J.; Elansezhian, R. Influence of dual reinforcement (nano $\mathrm{CuO}+$ reused spent alumina catalyst) on microstructure and mechanical properties of aluminium metal matrix composite. J. Alloy. Compd. 2020, 829, 154538. [CrossRef]

147. Singh, R.; Podder, D.; Singh, S. Effect of Single, Double and Triple Particle Size $\mathrm{SiC}$ and $\mathrm{Al}_{2} \mathrm{O}_{3}$ Reinforcement on Wear Properties of AMC Prepared by Stir Casting in Vacuum Mould. Trans. Indian Inst. Met. 2015, 68, 791-797. [CrossRef]

148. Logesh, K.; Hariharasakthisudhan, P.; Moshi, A.A.M.; Rajan, B.S.; Sathickbasha, K. Mechanical properties and microstructure of A356 alloy reinforced AlN/MWCNT/graphite/Al composites fabricated by stir casting. Mater. Res. Express 2019, 7, 15004. [CrossRef]

149. Viswanatha, B.M.; Kumar, M.P.; Basavarajappa, S.; Kiran, T.S. Study of the microstructure, hardness and tribological behavior of hypoeutectic Al-7Si hybrid composites. Ind. Lubr. Tribol. 2016. [CrossRef]

150. Venkatachalam, G.; Kumaravel, A. Fabrication and Characterization of A356-Basalt Ash-Fly Ash Composites Processed by Stir Casting Method. Polym. Polym. Compos. 2017, 25, 209-214. [CrossRef]

151. Prasad, D.S.; Shoba, C.; Ramanaiah, N. Investigations on mechanical properties of aluminum hybrid composites. J. Mater. Res. Technol. 2014, 3, 79-85. [CrossRef]

152. Lakshmikanthan, A.; Bontha, S.; Krishna, M.; Koppad, P.G.; Ramprabhu, T. Microstructure, mechanical and wear properties of the A357 composites reinforced with dual sized SiC particles. J. Alloy. Compd. 2019, 786, 570-580. [CrossRef]

153. Senthil Kumar, M.; Vanmathi, M.; Sakthivel, G. SiC Reinforcement in the Synthesis and Characterization of A356/AL2O3/Sic/Gr Reinforced Composite- Paving a Way for the Next Generation of Aircraft Applications. Silicon 2020, 4, 81. [CrossRef]

154. Ghanaraja, S.; Nath, S.K.; Ray, S. Processing and Mechanical Properties of Cast $\mathrm{Al}(\mathrm{Mg}, \mathrm{Mn})-\mathrm{Al}_{2} \mathrm{O}_{3}\left(\mathrm{MnO}_{2}\right)$ Composites Containing Nanoparticles and Larger Particles. Met. Mat. Trans. A 2014, 45, 3467-3480. [CrossRef]

155. Karantzalis, A.E.; Lekatou, A.; Georgatis, E.; Poulas, V.; Mavros, H. Microstructural Observations in a Cast Al-Si-Cu/TiC Composite. J. Mater. Eng. Perform. 2010, 19, 585-590. [CrossRef]

156. Natrayan, L.; Kumar, M.S.; Palanikumar, K. Optimization of squeeze cast process parameters on mechanical properties of $\mathrm{Al}_{2} \mathrm{O}_{3} / \mathrm{SiC}$ reinforced hybrid metal matrix composites using taguchi technique. Mater. Res. Express 2018, 5, 66516. [CrossRef]

157. Edacherian, A.; Algahtani, A.; Tirth, V. Investigations of the Tribological Performance of A390 Alloy Hybrid Aluminum Matrix Composite. Materials 2018, 11, 2524. [CrossRef] [PubMed] 
158. Heidary, D.S.B.; Akhlagh, F. Rheological behavior of molten Al-SiC slurries and comparison of their behavior with metallic slurries. Met. Mater. Int. 2013, 19, 767-775. [CrossRef]

159. Lü, S.; Xiao, P.; Du, Y.; Hu, K.; Wu, S. Preparation of Al matrix nanocomposites by diluting the composite granules containing nano-SiCp under ultrasonic vibaration. J. Mater. Sci. Technol. 2018, 34, 1609-1617. [CrossRef]

160. Wu, S.; Yuan, D.; Lü, S.; Hu, K.; An, P. Nano-SiC P particles distribution and mechanical properties of Al-matrix composites prepared by stir casting and ultrasonic treatment. China Foundry 2018, 15, 203-209. [CrossRef]

161. Bandil, K.; Vashisth, H.; Kumar, S.; Verma, L.; Jamwal, A.; Kumar, D.; Singh, N.; Sadasivuni, K.K.; Gupta, P. Microstructural, mechanical and corrosion behaviour of Al-Si alloy reinforced with SiC metal matrix composite. J. Compos. Mater. 2019, 53, 4215-4223. [CrossRef]

162. Altinkok, N. Application of the full factorial design to modelling of $\mathrm{Al}_{2} \mathrm{O}_{3} / \mathrm{SiC}$ particle reinforced al-matrix composites. Steel Compos. Struct. 2016, 21, 1327-1345. [CrossRef]

163. Ghahremanian, M.; Niroumand, B.; Panjepour, M. Production of Al-Si-SiCp cast composites by injection of low-energy ball-milled Al-SiCp powder into the melt. Met. Mater. Int. 2012, 18, 149-156. [CrossRef]

164. Al-Salihi, H.A.; Mahmood, A.A.; Alalkawi, H.J. Mechanical and wear behavior of AA7075 aluminum matrix composites reinforced by $\mathrm{Al}_{2} \mathrm{O}_{3}$ nanoparticles. Nanocomposites 2019, 5, 67-73. [CrossRef]

165. Dhaneswara, D.; Verdiyanto, R.N.; Syahrial, A.Z. The Mechanical Properties of $\mathrm{Al}_{2} \mathrm{O}_{3}$-Reinforced Aluminum A356 with Grain Refiner Al-5Ti-1B Fabricated using the Stir Casting Method. IJTech 2017, 8, 1489. [CrossRef]

166. Karbalaei Akbari, M.; Baharvandi, H.R.; Mirzaee, O. Nano-sized aluminum oxide reinforced commercial casting A356 alloy matrix: Evaluation of hardness, wear resistance and compressive strength focusing on particle distribution in aluminum matrix. Compos. Part B Eng. 2013, 52, 262-268. [CrossRef]

167. Su, H.; Gao, W.; Zhang, H.; Liu, H.; Lu, J.; Lu, Z. Optimization of Stirring Parameters Through Numerical Simulation for the Preparation of Aluminum Matrix Composite by Stir Casting Process. J. Mater. Process. Technol. 2010, 132, 144. [CrossRef]

168. Kaisarlis, G.; Vasiliou, G.; Spitas, V.; Inglezakis, V.; Itskos, G.; Spitas, C. Manufacturing of Ultra-Fine Particle Coal Fly Ash-A380 Aluminum Matrix Composites with Improved Mechanical Properties by Improved Ring Milling and Oscillating Microgrid Mixing. J. Mater. Eng. Perform. 2019, 28, 2630-2640. [CrossRef]

169. Lal, S.; Kumar, S.; Khan, Z.A. Microstructure evaluation, thermal and mechanical characterization of hybrid metal matrix composite. Sci. Eng. Compos. Mater. 2018, 25, 1187-1196. [CrossRef]

170. Golak, S.; Dyzia, M. Creating Local Reinforcement of a Channel in a Composite Casting Using Electromagnetic Separation. J. Mater. Sci. Technol. 2015, 31, 918-922. [CrossRef]

171. Zhang, D.; Nastac, L. Advanced Numerical Modeling of the Dispersion of Ceramic Nanoparticles during Ultrasonic Cavitation Processing and Solidification of 6061-based Nanocomposites. IOP Conf. Ser. Mater. Sci. Eng. 2015, 84, 12020. [CrossRef]

172. Su, H.; Gao, W.; Feng, Z.; Lu, Z. Processing, microstructure and tensile properties of nano-sized $\mathrm{Al}_{2} \mathrm{O}_{3}$ particle reinforced aluminum matrix composites. Mater. Des. 2012, 36, 590-596. [CrossRef]

173. Idrisi, A.H.; Mourad, A.-H.I. Conventional stir casting versus ultrasonic assisted stir casting process: Mechanical and physical characteristics of AMCs. J. Alloy. Compd. 2019, 805, 502-508. [CrossRef]

174. Jia, S.; Zhang, D.; Nastac, L. Experimental and Numerical Analysis of the 6061-Based Nanocomposites Fabricated via Ultrasonic Processing. J. Mater. Eng. Perform. 2015, 24, 2225-2233. [CrossRef]

175. Vorozhtsov, S.; Zhukov, I.; Promakhov, V.; Naydenkin, E.; Khrustalyov, A.; Vorozhtsov, A. The Influence of ScF3 Nanoparticles on the Physical and Mechanical Properties of New Metal Matrix Composites Based on A356 Aluminum Alloy. JOM 2016, 68, 3101-3106. [CrossRef]

176. Li, J.; Lü, S.; Wu, S.; Gao, Q. Effects of ultrasonic vibration on microstructure and mechanical properties of nano-sized SiC particles reinforced Al-5Cu composites. Ultrason. Sonochemistry 2018, 42, 814-822. [CrossRef]

177. Hanumanth, G.S.; Irons, G.A. Particle incorporation by melt stirring for the production of metal-matrix composites. J. Mater. Sci. 1993, 28, 2459-2465. [CrossRef]

178. Sukumaran, K.; Pillai, S.G.K.; Pillai, R.M.; Kelukutty, V.S.; Pai, B.C.; Satyanarayana, K.G.; Ravikumar, K.K. The effects of magnesium additions on the structure and properties of Al-7 Si-10 SiCp composites. J. Mater. Sci. 1995, 30, 1469-1472. [CrossRef]

179. Souissi, N.; Souissi, S.; Niniven, C.; Amar, M.; Bradai, C.; Elhalouani, F. Optimization of Squeeze Casting Parameters for 2017 A Wrought Al Alloy Using Taguchi Method. Metals 2014, 4, 141-154. [CrossRef]

180. Dao, V.; Zhao, S.; Lin, W.; Zhang, C. Effect of process parameters on microstructure and mechanical properties in AlSi9Mg connecting-rod fabricated by semi-solid squeeze casting. Mater. Sci. Eng. A 2012, 558, 95-102. [CrossRef]

181. Sajjadi, S.A.; Ezatpour, H.R.; Torabi Parizi, M. Comparison of microstructure and mechanical properties of A356 aluminum alloy $/ \mathrm{Al}_{2} \mathrm{O}_{3}$ composites fabricated by stir and compo-casting processes. Mater. Des. 2012, 34, 106-111. [CrossRef]

182. Shirvanimoghaddam, K.; Khayyam, H.; Abdizadeh, H.; Karbalaei Akbari, M.; Pakseresht, A.H.; Abdi, F.; Abbasi, A.; Naebe, M. Effect of $\mathrm{B} 4 \mathrm{C}, \mathrm{TiB}_{2}$ and $\mathrm{ZrSiO}_{4}$ ceramic particles on mechanical properties of aluminium matrix composites: Experimental investigation and predictive modelling. Ceram. Int. 2016, 42, 6206-6220. [CrossRef] 